\title{
Characteristics of local earthquake seismograms of varying dislocation sources in a stratified upper crust and modeling for $P$ and $S$ velocity structure: comparison with observations in the Koyna-Warna region, India
}

\author{
V. G. Krishna
}

Retd. CSIR - National Geophysical Research Institute, Hyderabad, India

\section{Article history}

Received December 24, 2014; accepted October 28, 2015.

Subject classification:

Seismology, Earthquake source and dynamics, Waves and wave analysis, Computational geophysics, Data processing.

\begin{abstract}
Vertical component record sections of local earthquake seismograms from a state-of-the-art Koyna-Warna digital seismograph network are assembled in the reduced time versus epicentral distance frame, similar to those obtained in seismic refraction profiling. The record sections obtained for an average source depth display the processed seismograms from nearly equal source depths with similar source mechanisms and recorded in a narrow azimuth range, illuminating the upper crustal $P$ and $S$ velocity structure in the region. Further, the seismogram characteristics of the local earthquake sources are found to vary significantly for different source mechanisms and the amplitude variations exceed those due to velocity model stratification. In the present study a large number of reflectivity synthetic seismograms are obtained in near offset ranges for a stratified upper crustal model having sharp discontinuities with 7\%-10\% velocity contrasts. The synthetics are obtained for different source regimes (e.g., strike-slip, normal, reverse) and different sets of source parameters (strike, dip, and rake) within each regime. Seismogram sections with dominantly strike-slip mechanism are found to be clearly favorable in revealing the velocity stratification for both $P$ and $S$ waves. In contrast the seismogram sections for earthquakes of other source mechanisms seem to display the upper crustal P phases poorly with low amplitudes even in presence of sharp discontinuities of high velocity contrasts. The observed seismogram sections illustrated here for the earthquake sources with strike-slip and normal mechanisms from the Koyna-Warna seismic region substantiate these findings. Travel times and reflectivity synthetic seismograms are used for 1-D modeling of the observed virtual source local earthquake seismogram sections and inferring the upper crustal velocity structure in the Koyna-Warna region. Significantly, the inferred upper crustal velocity model in the region reproduces the synthetic seismograms comparable to the observed sections for earthquake sources with differing mechanisms in the Koyna and Warna regions.
\end{abstract}

\section{Introduction}

Mobile seismograph networks in seismogenic regions provide significantly large database of local earth- quake seismograms. Record sections displaying the seismograms in the reduced time versus epicentral distance frame, similar to those obtained in seismic refraction profiling, can be assembled for an average source depth using the processed seismograms of earthquakes of nearly equal source depths with similar source mechanisms and recorded in a narrow azimuth range. Vertical component seismogram sections, assembled from a state-of-the-art Koyna-Warna digital seismograph network, illuminating the upper crustal structure demonstrate this approach. The Koyna-Warna seismic region located in the Western Ghats, in the south-western part of the Deccan Volcanic Province (DVP), in western India, reveals prolific seismicity confined to an area of $20 \times 30 \mathrm{~km}^{2}$ and mostly originating in the upper crustal depths up to $\sim 11 \mathrm{~km}$ in the north and $6-8 \mathrm{~km}$ in the south [Srinagesh and Sarma 2005]. Figure 1a shows the location map with the epicenters of some well-located earthquakes in the Koyna-Warna seismic region [Rai et al. 1999]. The seismicity pattern in this region starts as a single seismic tract in the north trending NE-SW, further branching into two distinct zones with NW-SE trend in the south (see inset in Figure 1a). Figure $1 \mathrm{~b}$ shows the depth distribution of seismicity in these three zones [Rai et al. 1999].

The Koyna-Warna seismic activity has been attributed to both regional tectonism [Wadia 1968, Krishna et al. 1973] and to reservoir-triggered seismicity [Gupta and Rastogi 1974, Gupta et al. 1980, Gupta 1992, Talwani 1997, Gupta 2002, Gupta 2005, Srinagesh and Sarma 2005, Shashidhar et al. 2011]. Rai et al. [1999] suggest that seismicity is related to lithology that extends into the lower crust. Gahalaut et al. [2004], Srinagesh and Sarma [2005], and Sarma and Srinagesh [2007] sug- 
(a)

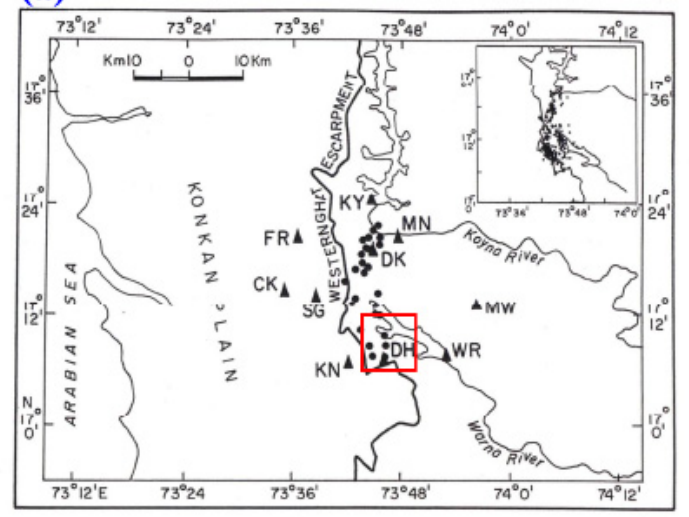

(c)

(b)
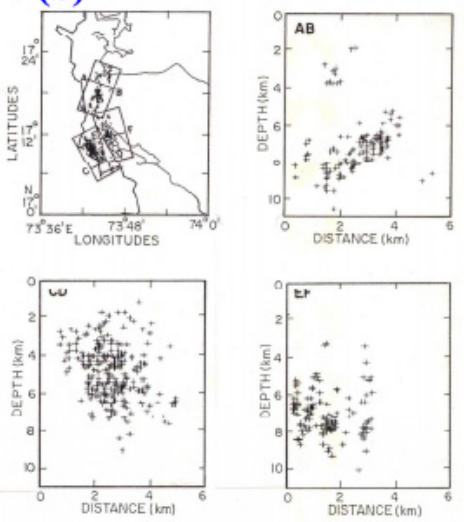

Figure 1. (a) Location map of the Koyna-Warna seismic region showing some of the seismograph stations (filled triangles) of the digital network operated, and the well located epicenters (filled circles) of the local earthquakes. The inset shows the observed seismicity pattern in the region described in the text. (b) Depth distribution of seismicity along three sections $\mathrm{AB}, \mathrm{CD}$, and EF observed in the region. (Figures 1a and 1b, after Rai et al. [1999]). (c) Composite source mechanism solutions for different earthquake clusters CI, C2, C3, and C8 in the Koyna, and C4, C5, C6, and C7 in the Warna seismic region (after Sharma [2000]).

gest that sustained seismicity in Koyna-Warna seismic zone is related to the geometry of existing faults and their interaction through stress transfer. Most researchers classify the seismicity as resulting from reservoir induced high pore pressure on existing stressed tectonic faults. The structure and nature of these faults, however, are poorly known because the entire Koyna-Warna region is covered at the surface by up to $\sim 1.5 \mathrm{~km}$ of Deccan Traps basalt. The ongoing seismic activity in the KoynaWarna region is primarily considered as the most outstanding example of reservoir-triggered seismicity [e.g., Gupta et al. 1969, Gupta et al. 1972, Gupta and Rastogi 1976, Gupta 1985, Gupta 1992, Talwani 1997, Gupta et al. 2012] essentially due to its proximity to the two reservoirs in the region, the Koyna (impoundment in 1962) and the Warna (impoundment in 1985). The seismicity in the Koyna region is considered to be possibly related to the presence of a large number of faults and lineaments, predominantly striking NNW-NE, inferred from LANDSAT images as well [Langston 1981]. The inferred faults and lineaments tend to define a broad en-echelon zone that parallels the Western Ghats in this area.

It is well known that essentially two different types of faulting mechanisms, strike-slip and normal dominate in the Koyna-Warna seismic region [Talwani 1997]. Further, there seems to be also a rapid variation of focal mechanisms from strike-slip type in the Koyna region earthquakes to normal type in the Warna region earthquakes [Talwani 1997, Sharma 2000, Srinagesh and Sarma 2005]. Figure 1c illustrates the rapid variation of the earthquake focal mechanisms from a predominantly strikeslip type in the north in the clusters C1, C2, C3, C8 in the Koyna region to a predominantly normal type in the south in the clusters $\mathrm{C} 4$, C5, C6, C7 in the Warna region (compiled by Sharma [2000]). A recent study by inversion of broad-band waveform data of Warna earthquakes also indicates predominantly normal type focal mechanism solutions, some having a component of strike-slip [Shashidhar et al. 2011].

Upper crustal $\mathrm{P}$ and $\mathrm{S}$ velocity structure can be inferred reliably from the observed seismogram sections assembled from local earthquake sources as well by the synthetic seismogram modeling techniques. It is important to note that the seismogram characteristics of the local earthquake sources vary drastically for different source mechanisms as will be shown here. The amplitude variations for varying source mechanisms may often exceed those expected from velocity model variations. Therefore in seismogenic regions of sharply varying source mechanisms (within a short distance range), it is necessary to assemble the seismogram sections separately for earthquakes of similar source mechanism. An understanding of local earthquake seismogram characteristics is important for determining the velocity structure models of the upper crust as well as the character and amplitude of near-source ground motions. The rupture directivity size, that controls the amplitude of near-source ground motion, depends on the dip angle and the direction of slip (rake angle) of the dislocation source [Aagaard et al. 2004]. Further, the local earthquake seismogram characteristics may vary significantly for different source regimes (e.g., strike-slip, normal or reverse) and even within each regime for different sets of source parameters (strike, dip, and rake) rather than depending only on the seismic velocity and Q structure of the 
host region. Some combinations of the source parameters of the upper crustal earthquakes may result in seismograms at local distances that do not reveal any signatures (like reflections and conversions) related to the vertically inhomogeneous seismic structure with presence of sharp interfaces of large velocity contrasts. A systematic study by numerical simulations for different source mechanisms can provide the necessary insight to understand the characteristics of local earthquake seismograms and their modeling for the upper crustal velocity structure. In the recent years, only a few studies [Oglesby et al. 2000, Aagaard et al. 2001a, Aagaard et al. 2001b, Aagaard et al. 2004] have systematically explored how the source parameters affect the near-source ground motions. Similar efforts for studying feasibility of velocity modeling of record sections of local earthquake seismograms for varying source regimes are, however, yet to be initiated. Because it is essential that the seismograms should be revealing and prominent phases as reflections, conversions and any other energetic phases generated by the existing velocity stratification are well recognized. A source effect leading to apparently missing or extremely low amplitude phases in a seismogram section should not be interpreted in terms of the velocity model features alone that suggest absence of prominent discontinuities. The source effect can be properly predicted by a systematic study of the characteristics of the seismograms for different source regimes.

In the present study we investigate this problem by a large number of numerical simulations. Reflectivity synthetic seismograms in near offset ranges are obtained for a stratified upper crustal model having sharp discontinuities with $7 \%-10 \% \mathrm{P}$ and $\mathrm{S}$ velocity contrasts. The synthetics are obtained for different source regimes (e.g., strike-slip, normal, reverse) as well as for different sets of source parameters (strike, dip, and rake) within each regime. The characteristics of local earthquake seismograms generated for different dislocation sources in a stratified upper crust are systematically examined. The scenarios considered vary from strike-slip to normal faulting regimes of the upper crustal seismogenic zones, besides a few dip-slip and reverse (thrust) faulting models. Various numerical simulations for different source regimes considered are obtained here for the same upper crustal P and S velocity models similar to those given by Krishna et al. [1999] for the 1993 Latur earthquake area in the Deccan Volcanic Province (DVP), in the western Indian shield. The P and S velocity models have sharp discontinuities with velocity contrasts of $7 \%-10 \%$ at the top and bottom boundaries of two prominent low-velocity layers (LVLs), i.e., with significant stratification in the upper crust. It is the pur- pose of the present study to examine how well the existing velocity stratification is revealed and can be modeled from the seismograms of local earthquakes for different source regimes considered. Seismogram sections of local earthquakes with dominantly strike-slip mechanism are found to be clearly favorable in revealing the velocity stratification in the upper crust for both $\mathrm{P}$ and $\mathrm{S}$ waves. In contrast the seismogram sections for earthquakes of other source mechanisms, particularly with rake angles around $\pm 90^{\circ}$, seem to display the upper crustal P and P-to-S converted phases poorly with low amplitudes even in presence of sharp discontinuities of high velocity contrasts. The significance of this study has been realized as several local earthquake seismogram sections are assembled in the KoynaWarna seismic region in the DVP and their modeling attempted for obtaining the upper crustal $\mathrm{P}$ and $\mathrm{S}$ velocity structure [Krishna, under review]. A few observed seismogram sections are illustrated here for the strikeslip and normal faulting regimes from the Koyna-Warna seismic region. The observed seismogram sections illustrated here for the earthquake sources with strikeslip and normal mechanisms from the Koyna-Warna seismic region in the Deccan volcanic province in the western Indian shield substantiate these findings. Travel times and synthetic seismogram computations by the reflectivity method, are used for 1-D modeling of the observed virtual source local earthquake seismogram sections and inferring the upper crustal velocity structure in the Koyna-Warna region. Significantly, the inferred velocity model for the upper crust in the region reproduces the synthetic seismograms comparable to the observed sections for earthquake sources with differing mechanisms in the Koyna and the Warna regions. Earlier studies [e.g., Talwani 1997, Sharma 2000, Srinagesh and Sarma 2005] in this region reveal left-lateral strike-slip faulting in the north and rapidly changing to normal faulting in the south escarpment zones of the Koyna seismic region, and normal faulting in the Warna seismic region as well.

\section{Local earthquake data set}

As more reliable data sets became available over time in the Koyna-Warna seismic region, location estimates steadily improved. The CSIR - National Geophysical Research Institute (NGRI) deployed a temporary seismic network consisting of 20 stations during 19961998, and Rai et al. [1999] used some of those stations to relocate more than 400 of the recorded events. Their events had estimated timing errors less than a few milliseconds, and $93 \%$ of their events had epicentral resolutions of $0.2 \mathrm{~km}$ or less and hypocentral resolutions of $1.0 \mathrm{~km}$ or less, but the locations were based on only about 


\begin{tabular}{|c|c|c|c|c|c|c|}
\hline \multirow{2}{*}{ EQ no. } & \multirow{2}{*}{ Cluster } & \multicolumn{2}{|c|}{ Epicenter } & \multirow{2}{*}{$\begin{array}{l}\text { Focal depth } \\
\qquad(\mathrm{km})\end{array}$} & \multirow{2}{*}{$\begin{array}{l}\text { Magnitude } \\
\text { (Mcoda) }\end{array}$} & \multirow{2}{*}{$\begin{array}{l}\text { Epicentral distances } \\
\qquad(\mathrm{km})\end{array}$} \\
\hline & & Lat. $^{\circ}$ & Long. ${ }^{\circ}$ & & & \\
\hline \multicolumn{7}{|c|}{ Record section CK-FR-SG (Figure 9a) } \\
\hline 9 & C3 & 17.32 & 73.74 & 8.9 & 1.6 & $18.1,12.8,13.7$ \\
\hline 23 & C3 & 17.28 & 73.74 & 7.3 & 1.6 & $16.3,14.4,10.7$ \\
\hline 24 & C3 & 17.28 & 73.73 & 7.4 & 2.4 & \\
\hline 25 & $\mathrm{C} 2$ & 17.35 & 73.75 & 8.2 & 2.1 & $20.7,13.9,16.7$ \\
\hline 30 & C3 & 17.30 & 73.73 & 8.0 & 1.9 & $16.5,13.2,11.5$ \\
\hline 36 & $\mathrm{C} 2$ & 17.33 & 73.73 & 7.8 & 2.3 & $12.0,14.1$ \\
\hline \multicolumn{7}{|c|}{ Record section CK-FR (Figure 10a) } \\
\hline 21 & $\mathrm{C} 4$ & 17.23 & 73.72 & 8.5 & 1.9 & $17.0,13.5$ \\
\hline 26 & C5 & 17.20 & 73.76 & 7.4 & 2.6 & 22.1 \\
\hline 39 & C5 & 17.22 & 73.76 & 7.7 & 1.6 & 20.2 \\
\hline
\end{tabular}

Table 1. Koyna (clusters C2, C3) and Warna (clusters C4, C5) earthquakes (EQ) data for the seismogram sections CK-FR-SG, CK-FR, for an average source depth of $8 \mathrm{~km}$.

six stations. Srinagesh and Sarma [2005] and Sarma and Srinagesh [2007] applied double-difference methodology in more precisely relocating more than 600 earthquakes from this dataset. Shashidhar et al. [2011] used the VELEST algorithm to jointly locate hypocenters and to determine the velocity structure in the KoynaWarna area, and their data were recorded on 11 seismographs. In an attempt to better characterize the seismogenic crust in the Koyna-Warna region, Dixit et al. [2014] recently acquired seismic data using a portable network consisting of 97 Taurus $®$ seismographs, which is claimed to be denser than the previously deployed networks in the area.

In the present study, we utilize the vertical component seismograms of local earthquakes well recorded by a state-of-the-art Koyna digital seismograph network deployed by CSIR-NGRI during 1996-1998 [Rai et al. 1999]. The events were recorded (at 100 samples/s) by various stations of the seismograph network equipped with 24 bit REFTEK/PASSCAL digital recorders of short period three-component seismometers and GPS timing system. Figure 1a shows the location map of the Koyna-Warna seismic region with the epicenters of the local earthquakes and the seismograph stations used in the present study. The inset shows the observed seismicity pattern in this region. Table 1 gives the epicentral data of the local earthquakes in the Koyna (clusters C2, C3) and Warna (clusters C4, C5) regions considered here for creating the two vertical component seismic record sections CK-FR-SG, and CK-FR for an average source depth of $8 \mathrm{~km}$.

Statistical analysis of a dataset of about 400 local earthquakes of the region by Rai et al. [1999] reveals well-constrained estimates of the epicentral locations and the hypocentral depths for various events in the depth range to $\sim 11 \mathrm{~km}$ of the seismogenic upper crust. Srinagesh and Sarma [2005] relocated more than 600 earthquakes in the Koyna-Warna seismic zone, separately for three spatially distinct clusters, namely the north escarpment zone (NEZ), south escarpment zone (SEZ) and Warna seismic zone (WSZ), based on the inferences by Rai et al. [1999] during the analysis of seismicity patterns in this region. The constrained focal mechanisms show distinct styles of faulting amongst the various fault segments with NEZ predominantly showing the strike-slip faulting with left lateral motion on the NE-SW fault. In SEZ and WSZ the focal mechanisms are basically normal on the steeply dipping NNW-SSE to N-S faults [Srinagesh and Sarma 2005]. The epicentral-hypocentral resolutions estimated by Rai et al. [1999] are found to be good enough for various events considered for investigating the problem

\begin{tabular}{ccccc}
\hline Cluster & $\begin{array}{c}\text { Focal depth } \\
(\mathrm{km})\end{array}$ & Strike $^{\circ}$ & Dip $^{\circ}$ & Rake $^{\circ}$ \\
\hline C1 & $4-7$ & 40 & 90 & 10 \\
C2 & $7-11$ & 30 & 82 & 6 \\
C3 & $7-11$ & 30 & 82 & 6 \\
C8 & $1-4$ & 50 & 85 & 9 \\
C4 & $1-11$ & 340 & 50 & -90 \\
C5 & $1-11$ & 340 & 50 & -90 \\
C6 & $1-11$ & 340 & 50 & -90 \\
C7 & $1-11$ & 340 & 50 & -90 \\
\hline
\end{tabular}

Table 2. Source parameters for various earthquake clusters in the Koyna-Warna seismic region (after Sharma [2000]). 
being addressed in the present study, and thus no attempts are made here to further relocate the hypocentral parameters. The results of a preliminary study of composite focal mechanism solutions obtained by Sharma [2000] are given in Table 2, at different depth ranges of the spatially different clusters shown in Figure 1c. As shown in Figure 1c, analysis of the composite fault-plane solutions in the Koyna-Warna seismic region reveals two distinct faulting mechanisms, predominantly left-lateral strike-slip faulting in the Koyna region in the north rapidly changing to predominantly normal faulting in the Warna region in the south.

\section{Characteristics of seismograms of local earthquake sources with different source mechanisms in a strati- fied upper crust}

In order to examine the influence of different source mechanisms on the observed local earthquake seismograms for a stratified upper crustal structure with presence of sharp velocity discontinuities (e.g., with $\mathrm{P}$ and $S$ velocity contrasts up to $7 \%-10 \%$ ), a simulation study is thus attempted as shown in the following. A good number of reflectivity synthetic seismogram sections are obtained for different source regimes (e.g., strikeslip, normal, reverse) as well as for different sets of source parameters (strike, dip, and rake) within each regime for the same model of $\mathrm{P}$ and $\mathrm{S}$ velocity structure given in Figure 2. The characteristics of the local earthquake seismograms, as will be shown here, vary significantly for different source mechanisms. The amplitude variations for varying source mechanisms may often exceed those expected from velocity model variations. Therefore in seismogenic regions of rapidly varying source mechanisms within a short distance range, specifically in the Koyna-Warna seismic region of the present study, it is indeed necessary to assemble the seismogram sections separately for earthquakes of similar source mechanism.

3.1. Synthetic seismogram gathers for varying source parameters - A simulation study

A large number of reflectivity synthetic seismograms [Kind 1985, Müller 1985] are computed in near offset ranges out to about $40 \mathrm{~km}$ for an arbitrary $6 \mathrm{~km}$ deep earthquake source in the upper crust with the vertically inhomogeneous $P$ and $S$ velocity models shown in Figure 2. A double-couple point source with the source-time function of Brüstle and Müller [1983] is used for various computations. Source mechanisms similar to the strike-slip, normal, reverse, and dip-slip models are considered for different computations. In each case the set of source parameters (strike, dip, and rake) are systematically varied (at $10^{\circ}-20^{\circ}$ intervals) and the

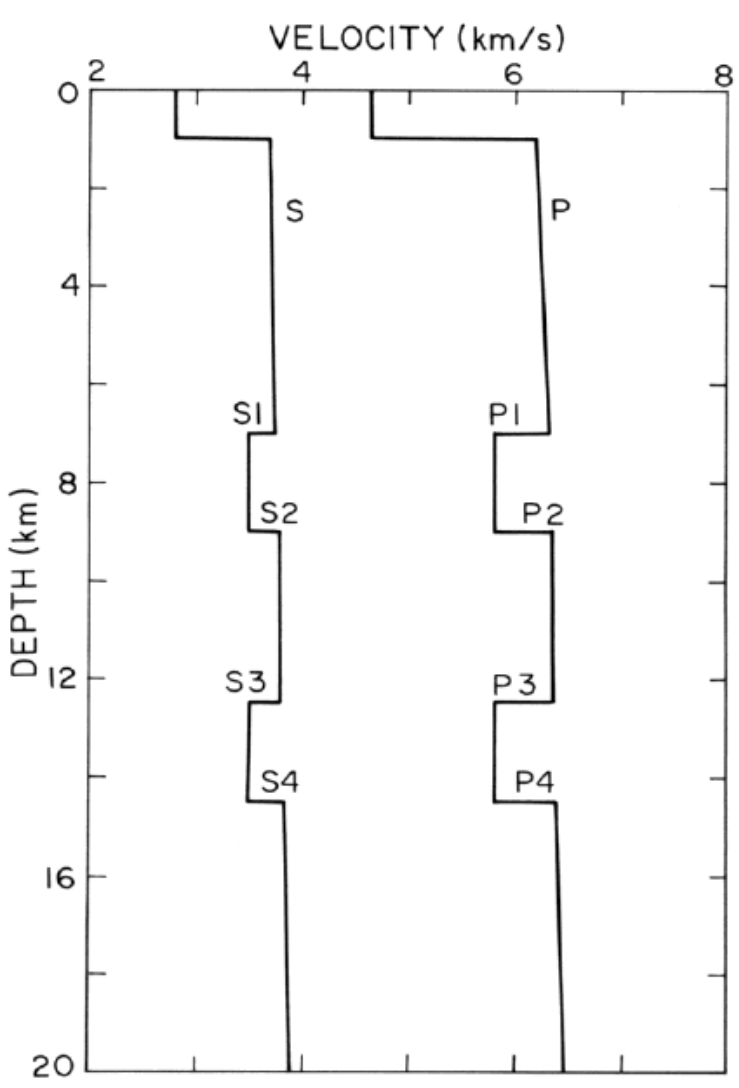

Figure 2. Upper crustal $\mathrm{P}$ and $\mathrm{S}$ velocity models used to compute the synthetic seismogram gathers shown in Figures 3-7 to illustrate variations of the local earthquake seismogram characteristics for different source mechanisms. Note the significant stratification in the upper crust that is examined as to how well the $\mathrm{P}$ and $\mathrm{S}$ reflections and the P-to-S conversions can be recognized in various synthetics for different source mechanisms.

synthetics are obtained for several combinations. While a $Q_{\mathrm{P}} / \mathrm{Q}_{\mathrm{S}}$ ratio of $9 / 4$ is used in all the computations other ratios, e.g., 1 and $1 / 2$ are used for a set of strike-slip and normal mechanisms to examine the resulting seismograms. Various synthetics obtained as described above are displayed by using identical scaling of the true amplitudes, so that the seismogram sections shown in the following may be directly compared.

Figures 3-7 show the vertical component reflectivity synthetic seismogram gathers (true-amplitude plots with reduction velocity $6 \mathrm{~km} / \mathrm{sec}$ ) for the common offset range of $28 \mathrm{~km}$. The theoretical travel-times computed for the $V_{P}$ and $V_{S}$ models (given in Figure 2) are also shown as indicated on various seismograms by their onsets (P and S: refractions; P1, P2, P3, P4, and S1, S2, S3, S4: primary reflections). The source parameters, for which the seismograms are generated, are indicated with each gather in Figures 3-7. Each of the gathers illustrates variation of the seismogram characteristics with variation of one of the source parameters, with the other two parameters remaining unchanged.

Figures $3 \mathrm{a}$ and $3 \mathrm{~b}$ and Figures $4 \mathrm{a}$ and $4 \mathrm{~b}$ reveal the seismogram characteristics varying due to the rake 

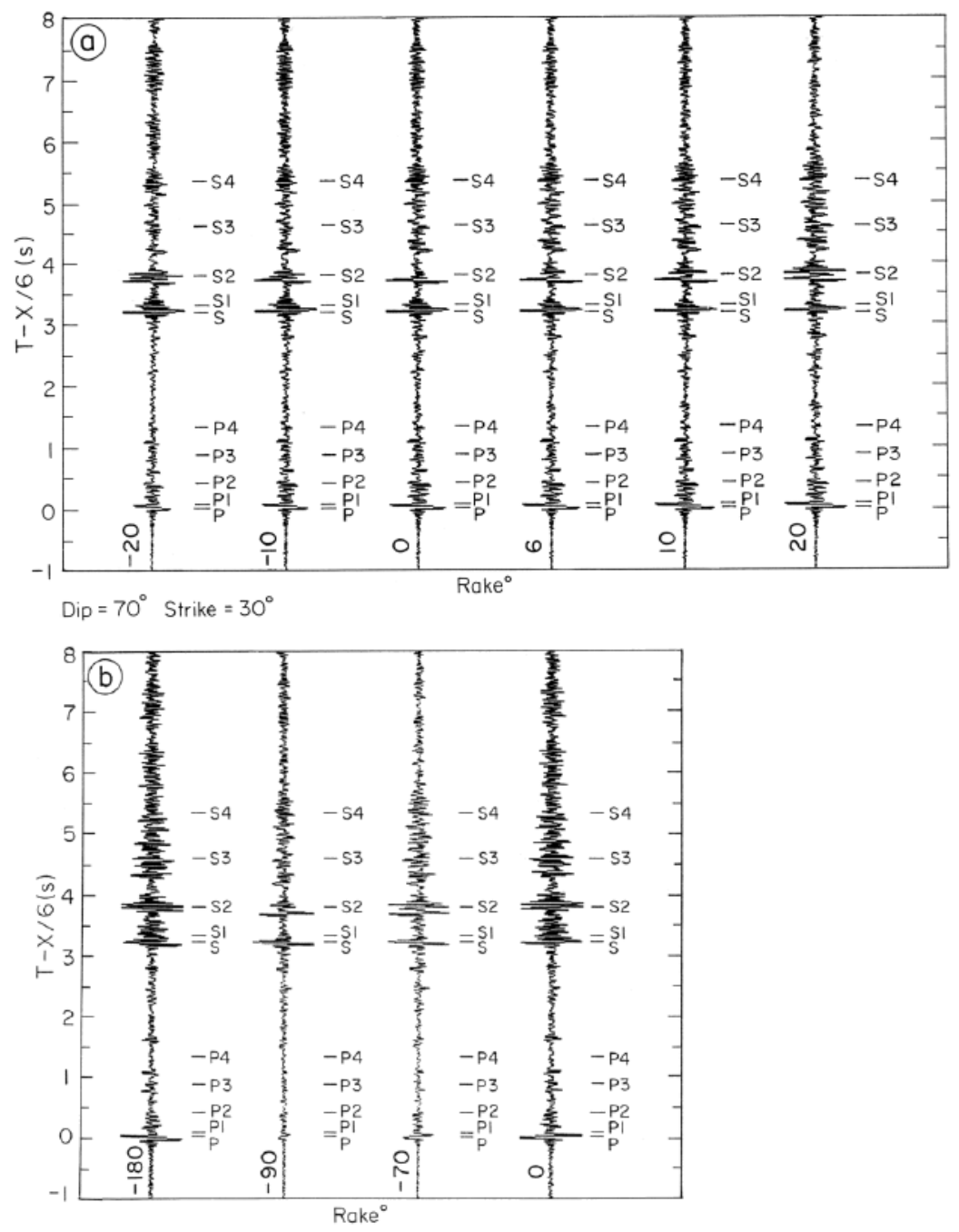

Dip $=60^{\circ}$ Strike $=320^{\circ}$

Figure 3. (a) Vertical-component reflectivity seismograms gather (true amplitudes plot with reduction velocity $6 \mathrm{~km} / \mathrm{sec}$ ) for a common offset range of $28 \mathrm{~km}$ showing amplitude variations of different phases due to rake angle variations of various source mechanisms. All the seismograms are computed for the source depth of $6 \mathrm{~km}$ using the P and S velocity models shown in Figure 2. Onsets of various travel-time branches are given to the right of the seismograms. Note the P phase amplitudes are however recognizable for rake angles in the range of at least $-20^{\circ}$ to $+20^{\circ}$. (b) Same as Figure 3 a for the normal faulting mechanism. Note very low amplitude P phases for the intermediate rake angles near $-90^{\circ}$.

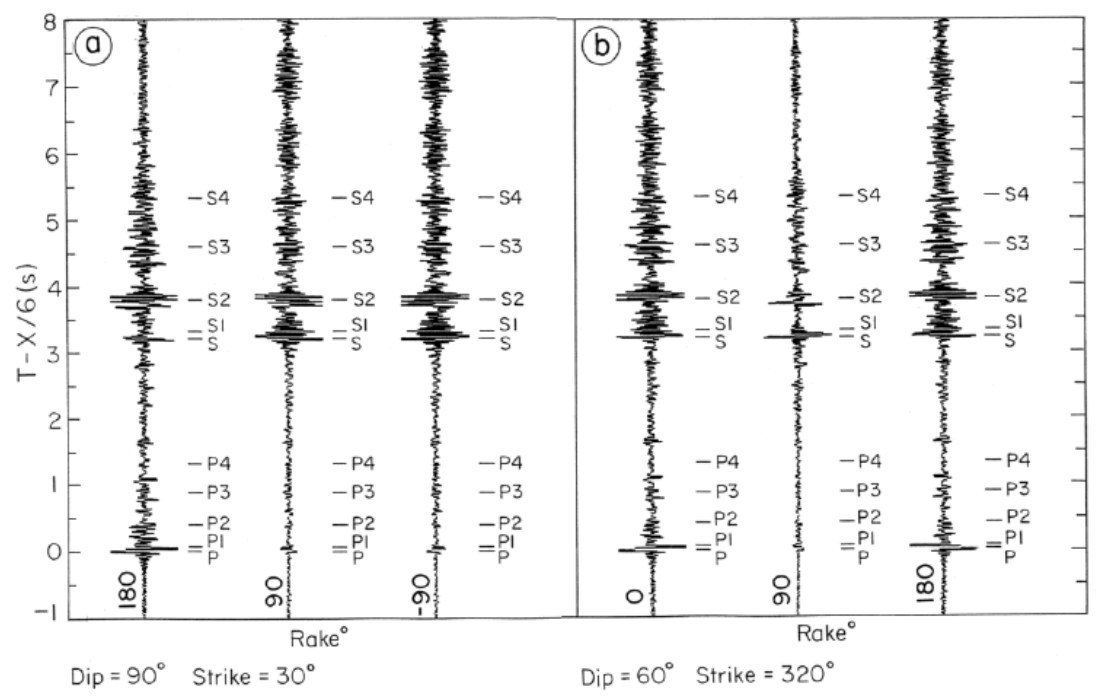

Figure 4. (a) Same as Figure 3a for the right-lateral strike-slip $\left(\right.$ rake $180^{\circ}$ ) and the dip-slip (rake $\pm 90^{\circ}$ ) mechanism. Note very low amplitude $\mathrm{P}$ phases and relatively high amplitude $\mathrm{S}$ phases for the rake angles $\pm 90^{\circ}$. (b) Same as Figure 3 a for the reverse (thrust) mechanism. Note very low amplitude $\mathrm{P}$ phases for the intermediate rake angle $90^{\circ}$. 
angle variations for the strike-slip, normal, reverse, and dip-slip mechanisms. It is clear that the amplitudes of the $\mathrm{P}$ phases (refractions and reflections) as well as the P-to-S conversions are significantly low for the intermediate rake angles around $\pm 90^{\circ}$ and these phases are recognizable only for the extreme rake angles around $\pm 180^{\circ}$ and $0^{\circ}$. Seismograms for the strike-slip mechanisms generally appear to be favorable for revealing the phases of $\mathrm{P}$ velocity stratification (see Figure $3 \mathrm{a}$ for the left-lateral strike-slip case, and the seismogram for rake angle $180^{\circ}$ in Figure 4 a for the right-lateral strike-slip case). The $S$ phases do not reveal significant amplitude variations as the $\mathrm{P}$ phases, although for intermediate rake angles around $\pm 90^{\circ}$ they are relatively low for the normal and reverse mechanisms.

Variations of the seismogram characteristics due to the dip angle variations are illustrated in Figures 5a and $5 \mathrm{~b}$ for the strike-slip and the normal mechanisms. Amplitudes of the P phases and the P-to-S conversions are relatively low for the normal mechanisms as compared to the strike-slip mechanisms. However the amplitudes of the $S$ phases are stronger for the normal mechanisms. It is again clear that the seismograms for the strike-slip mechanisms appear to be more favorable to delineate both $\mathrm{P}$ and $\mathrm{S}$ velocity stratification. Similar differences, especially concerning the P phase amplitudes, between the seismograms for the strike-slip and normal mechanisms are also evident from Figures $6 \mathrm{a}$ and $6 \mathrm{~b}$. In these figures the seismograms are shown for varying strike but the same dip and rake angles.

Figure 7 shows the differences between the seismograms for the strike-slip and normal mechanisms for varying $\mathrm{Q}_{\mathrm{p}} / \mathrm{Q}_{\mathrm{S}}$ ratio. The source parameters (strike, dip, and rake) of the two source regimes considered here cor- respond to those inferred for some upper crustal earthquakes in the Koyna-Warna seismic region of the DVP in the western Indian shield [Sharma 2000]. $Q_{p} / Q_{S}$ ratios in the upper crustal layers equal to or even less than 1 are not uncommon and similar ratios have been found in the 1993 Latur earthquake area of the DVP [Krishna et al. 1999], and the eastern Dharwar craton [Krishna and Ramesh 2000] in the South Indian shield. Similar smaller $Q_{p} / Q_{S}$ ratios, if exist in the Koyna-Warna region, may further degenerate the amplitudes of the $P$ phases in the seismograms of the events with normal mechanisms as can be seen from Figure $7 \mathrm{~b}$.

The major result of interest in this simulation study is that, seismogram sections of local earthquakes with dominantly strike-slip mechanism are clearly favorable in revealing the velocity stratification in the upper crust for both $P$ and $S$ waves. In contrast the seismogram sections for earthquakes of other source mechanisms, particularly with rake angles around $\pm 90^{\circ}$, seem to display the upper crustal reflected $\mathrm{P}$ and P-to-S converted phases poorly with low amplitudes even in presence of sharp discontinuities of high velocity contrasts. Thus it is clearly necessary to assemble the seismogram sections from local earthquakes of similar source mechanisms for recognizing prominent phases from potential velocity discontinuities and their modeling leading to reliable upper crustal $P$ and $S$ velocity structure.

\section{Modeling of the Koyna-Warna local earthquake seismogram sections}

The development of 1-D crustal velocity models, particularly in seismogenic regions as the Koyna-Warna region, is the basis for a range of applications in earthquake seismology. A well-developed 1-D crustal model

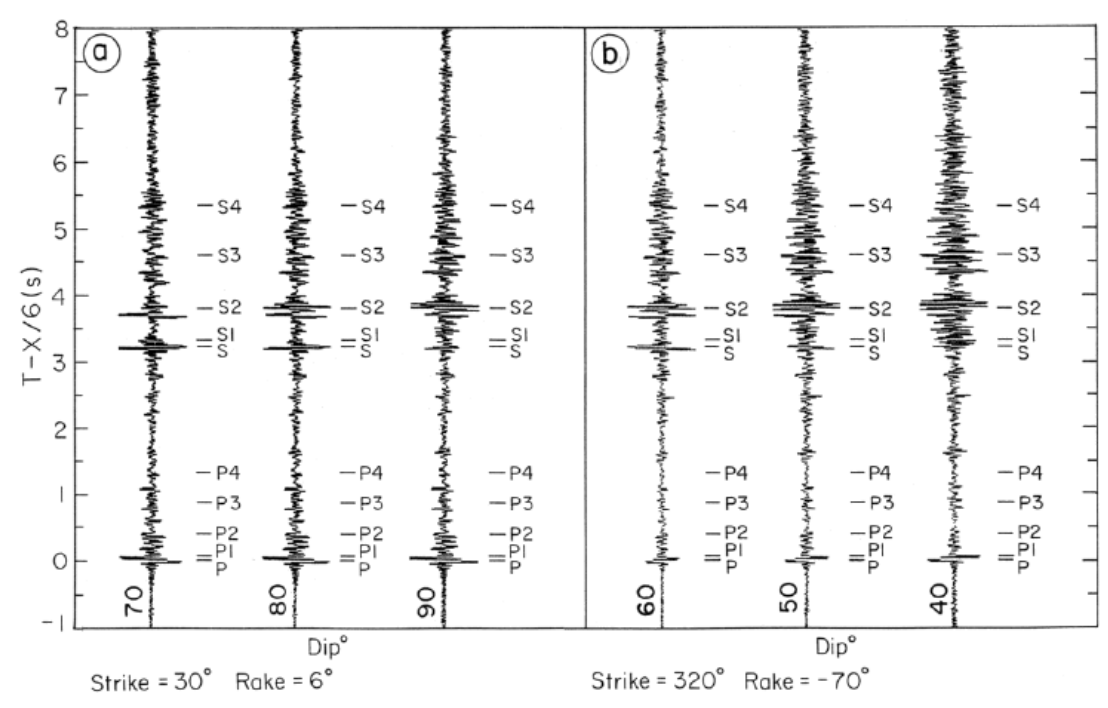

Figure 5. Same as Figure 3a showing amplitude variations due to dip angle variations for (a) strike-slip, and (b) normal mechanisms. Note higher amplitude P phases for the strike-slip mechanism. 

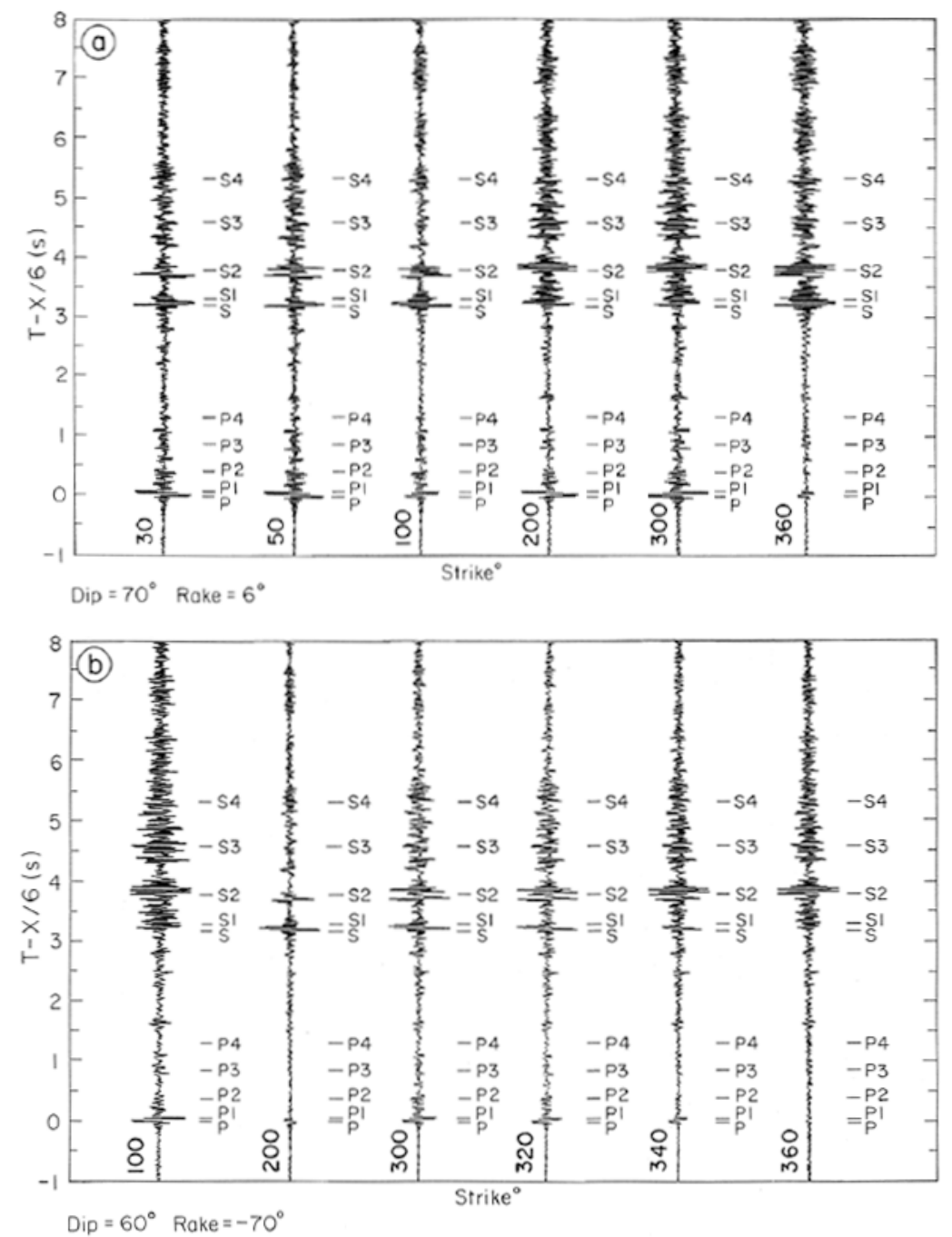

Figure 6. (a) Same as Figure 3a showing amplitude variations as the strike varies for the strike-slip mechanism. (b) Same as Figure 6a for the normal mechanism. Note relatively low amplitude P phases as compared to those for the strike-slip mechanism.

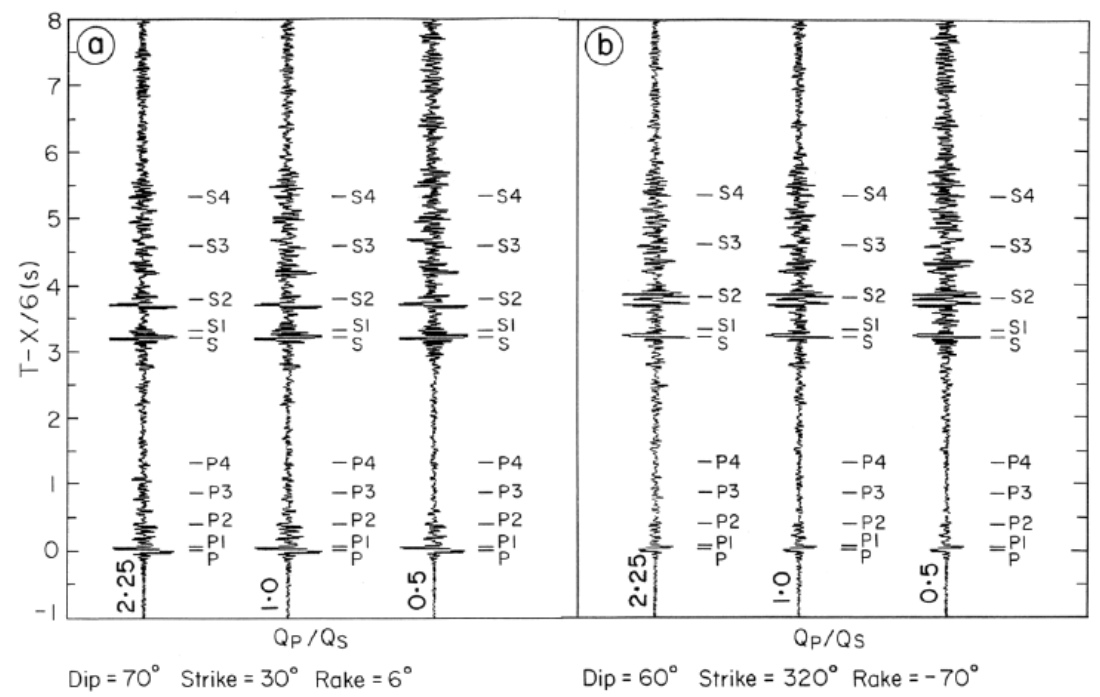

Figure 7. Same as Figure 3a showing amplitude variations due to different $\mathrm{Q}_{\mathrm{P}} / \mathrm{Q}_{\mathrm{S}}$ ratios in seismograms for (a) strike-slip, and (b) normal mechanism. Note higher amplitude P phases for the strike-slip mechanism.

has been widely used to determine the source parameters of earthquakes. The computational efficiency to calculate Green's functions is a primary advantage of the
1-D model, which can be used in studies of the rupture processes of earthquakes [e.g., Hartzell and Heaton 1983, Dreger and Helmberger 1993]. Furthermore, the 1-D 


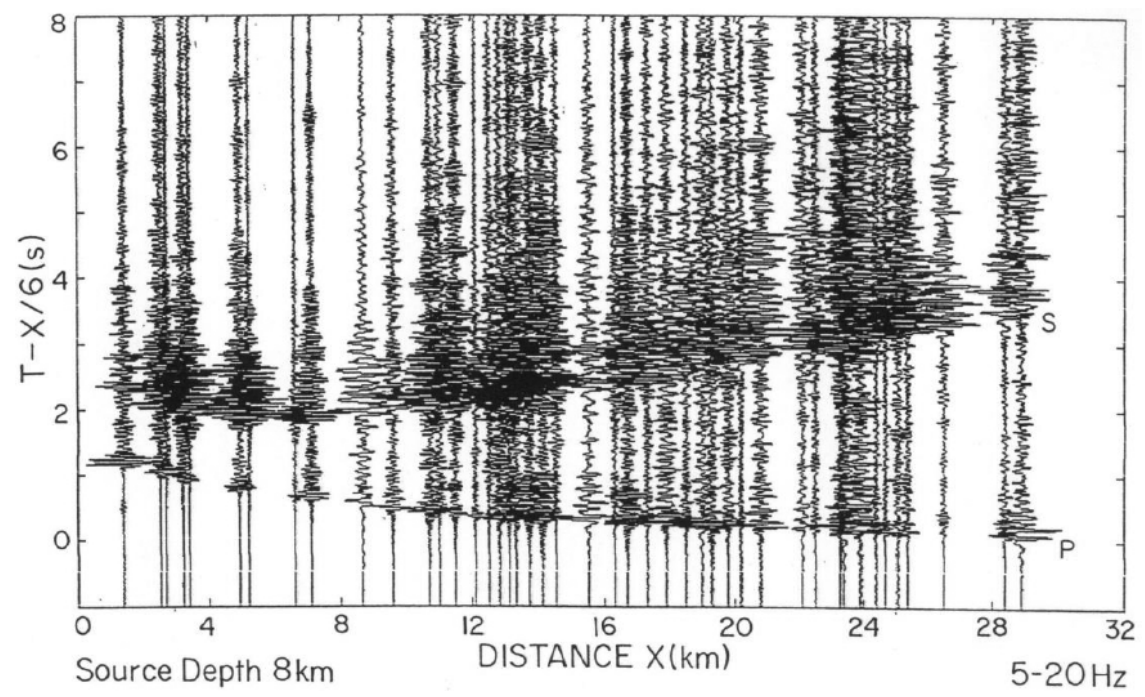

Figure 8. Composite observed record section with amplitudes normalized, in the epicentral distance versus reduced time (reduction velocity $6 \mathrm{~km} / \mathrm{s}$ ) frame, assembled from processed seismograms of local earthquakes with average source depth of $8 \mathrm{~km}$.

model can be used as an initial model for developing more complex 2-D and 3-D velocity models. The traditional way to develop a 1-D velocity model utilizes the traveltimes of seismic phases. Synthetic seismograms modeling is recognized as the more efficient technique to determine the velocity structure mitigating nonuniqueness of the models obtained from the arrival times of a few recognized phases.

By the approach given by Krishna et al. [1999] seismogram sections in near distance ranges are assembled for a few common source depths using well located earthquakes with hypocentral depths agreeing within $1 \mathrm{~km}$. Figure 8 illustrates one such composite section for a common source depth of $8 \mathrm{~km}$ assembled for earthquakes recorded by various stations in the region. This record section is considered as a composite section generated by a virtual source at $8 \mathrm{~km}$ depth, because this section includes the seismograms from various azimuths and also those for different source mechanisms. It is clear that the direct and refracted $\mathrm{P}$ and $\mathrm{S}$ phases are well aligned in this section. However, any later arriving phases, in the $\mathrm{P}$ and $\mathrm{S}$ windows, may not be evidently recognizable in this section. Therefore it is considered necessary to assemble only seismograms for a similar source depth as well as similar source mechanism and recorded in a narrow azimuth range from various seismograph stations. The earthquake epicentral data used for this purpose are given in Table 1. The record sections thus assembled are shown in Figure 9a for events with dominantly strike-slip mechanism and in Figure 10a for events with normal mechanism. These record sections are band-pass filtered $(5-20 \mathrm{~Hz})$ and plotted with a reduction velocity of 6 $\mathrm{km} / \mathrm{sec}$ and amplitudes trace-normalized. Significant variations in the seismogram characteristics as described in the earlier sections are clearly observable in the record sections for the strike-slip (Figure 9a) and normal events (Figure 10a). It should be considered here that the crustal volume sampled by the ray paths involved for the seismograms shown in Figures 9a and 10a is of limited dimensions only. Thus it is quite unlikely that the observed systematic variations of the seismogram characteristics can be caused by lateral velocity perturbations. Both $\mathrm{P}$ and $\mathrm{S}$ velocity tomographic inversion using local earthquake arrival times revealed a maximum lateral variation of about $4 \%$ [Rai et al. 1999]. Further P and S velocity-depth profiles modeled in the nearby 1993 Latur earthquake area of the DVP [Krishna et al. 1999] reveal significant stratification of the upper crust with presence of prominent discontinuities having velocity contrasts of about $7 \%$. The $V_{\mathrm{P}}$ and $\mathrm{V}_{\mathrm{S}}$ models similar to those given in Figure 2, used for computation of travel time curves in Figures $9 \mathrm{a}$ and 10a also indicate similar order of the velocity contrasts at various interfaces in the upper crust in the Koyna region as well [Krishna 2006]. The high amplitude secondary phases in Figure 9a fit the P2, P3, $\mathrm{P} 4$, and S2, S3, S4 travel-time curves which are primary reflections at the discontinuities with similar order of velocity contrasts. These travel-time curves shown in Figure 10a also fit the lower amplitude secondary phases correlated in the record section. It is only the different source mechanism that causes the apparently low amplitudes of the secondary phases. Synthetic seismograms thus obtained clearly resolve this problem by generating low amplitude secondary phases even in presence of discontinuities with similar high velocity contrasts. Therefore the local earthquake seismogram sections as shown in Figure 10a should be modeled only by considering the appropriate source mechanism, otherwise the existing stratification in the upper crust may be misinterpreted as a vertically ho- 
(a)

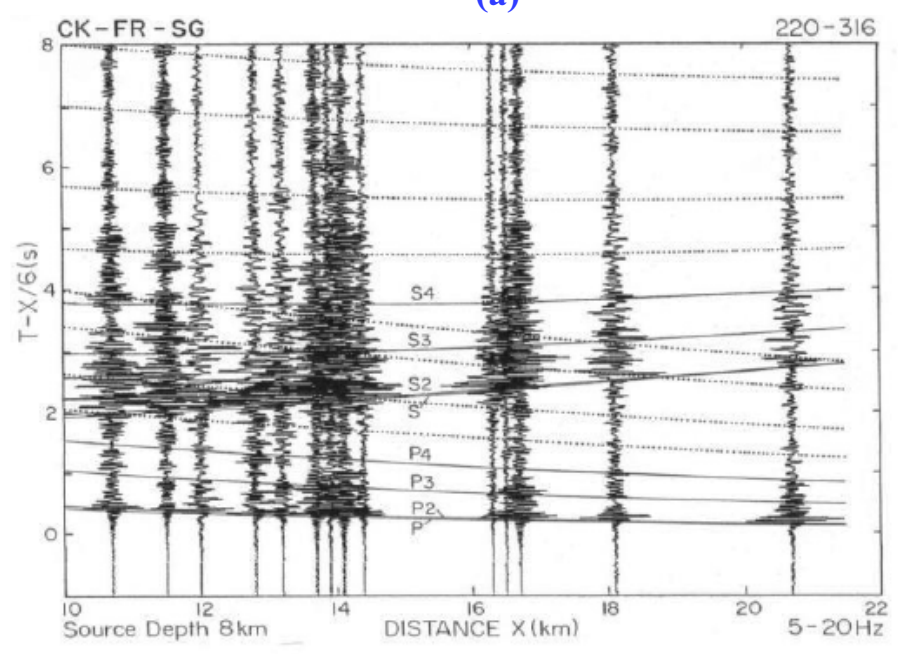

(b)
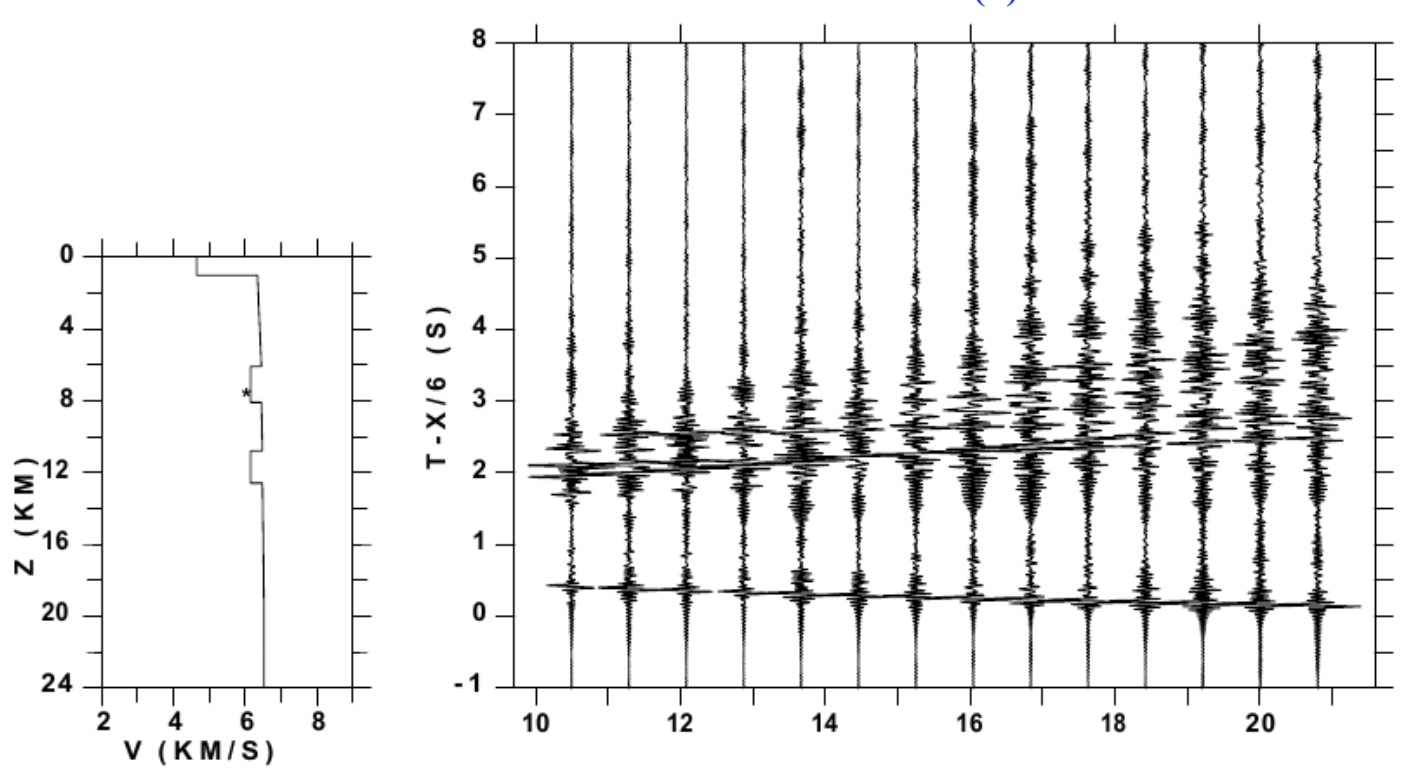

Figure 9. (a) Observed record section assembled from seismograms of local earthquakes with similar source mechanisms (the dominant mechanism is strike-slip), aligned to an average source depth of $8 \mathrm{~km}$, and recorded at a combination of the seismograph stations CK, FR, and SG in the Koyna-Warna region. A reduction velocity of $6 \mathrm{~km} / \mathrm{sec}$ is used for plotting. The amplitudes are trace-normalized. A band-pass filter $5-20 \mathrm{~Hz}$ is applied. Computed travel-time curves are shown for direct and refracted $\mathrm{P}$ and $\mathrm{S}$ phases, and primary reflection phases $\mathrm{Pi}$ and $\mathrm{Si}$, as well as for the $\mathrm{P}$ and $\mathrm{S}$ phases leaving the source and reflected at the free-surface followed by reflection at an upper crustal boundary (unlabeled dotted curves in the time-increasing-order for reflections PfPi and SfSi, [i=1-4]). The seismograph stations and their azimuth range are indicated on the top of the record section. (b) Synthetic seismogram section computed by the reflectivity method for the virtual source parameters and using the inferred models of the upper crustal $\mathrm{P}$ and $\mathrm{S}$ velocity structure in the region. The amplitudes are trace-normalized. The left panel shows the P velocity model.

mogeneous medium. This is particularly applicable for regions like the Koyna-Warna seismic zones where the source mechanisms sharply vary from strike-slip to normal within a short distance range.

The methodology for modeling the record sections in the present study is as follows. Preliminary determinations of layer parameters are obtained from travel times modeling for inferring Earth's structure. Further, synthetic seismograms are computed using the inferred $\mathrm{P}$ and $\mathrm{S}$ velocity models and initial set of source parameters (strike, dip, and rake) appropriate for the source depth of the record section. Several for- ward problem runs are made by varying the source parameters to improve the synthetics in explaining various features of the seismogram. In the following, 1-D model computational results of the travel times and synthetic seismograms are presented for modeling the record sections of local earthquake seismograms available out to a maximum range of about $22 \mathrm{~km}$ as shown in Figures 9 and 10. The virtual source parameters inferred from modeling of these record sections are further used to compute synthetics. By this modeling approach, plausible models of the $\mathrm{P}$ and $\mathrm{S}$ velocity structure of the upper crust are inferred. 
(a)

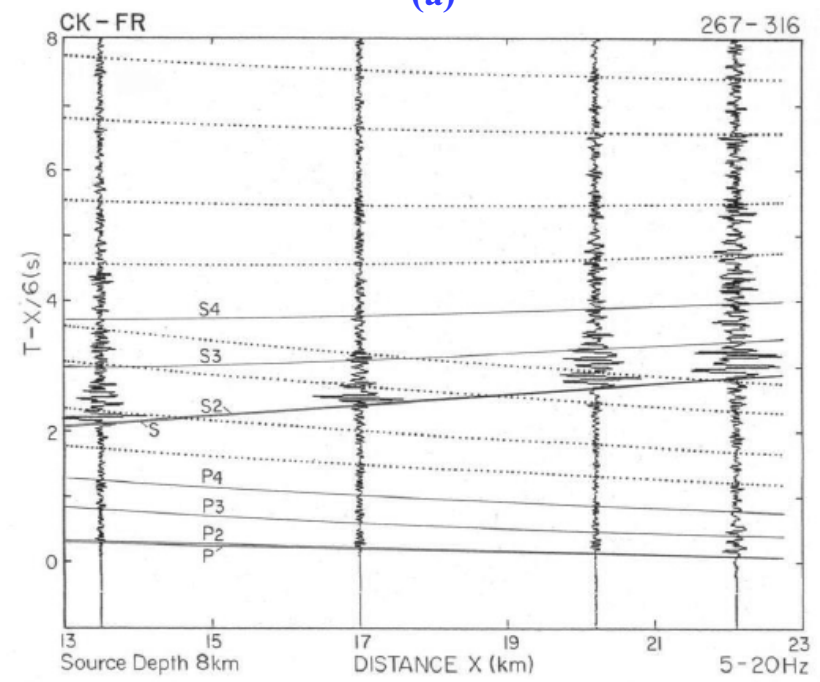

(b)
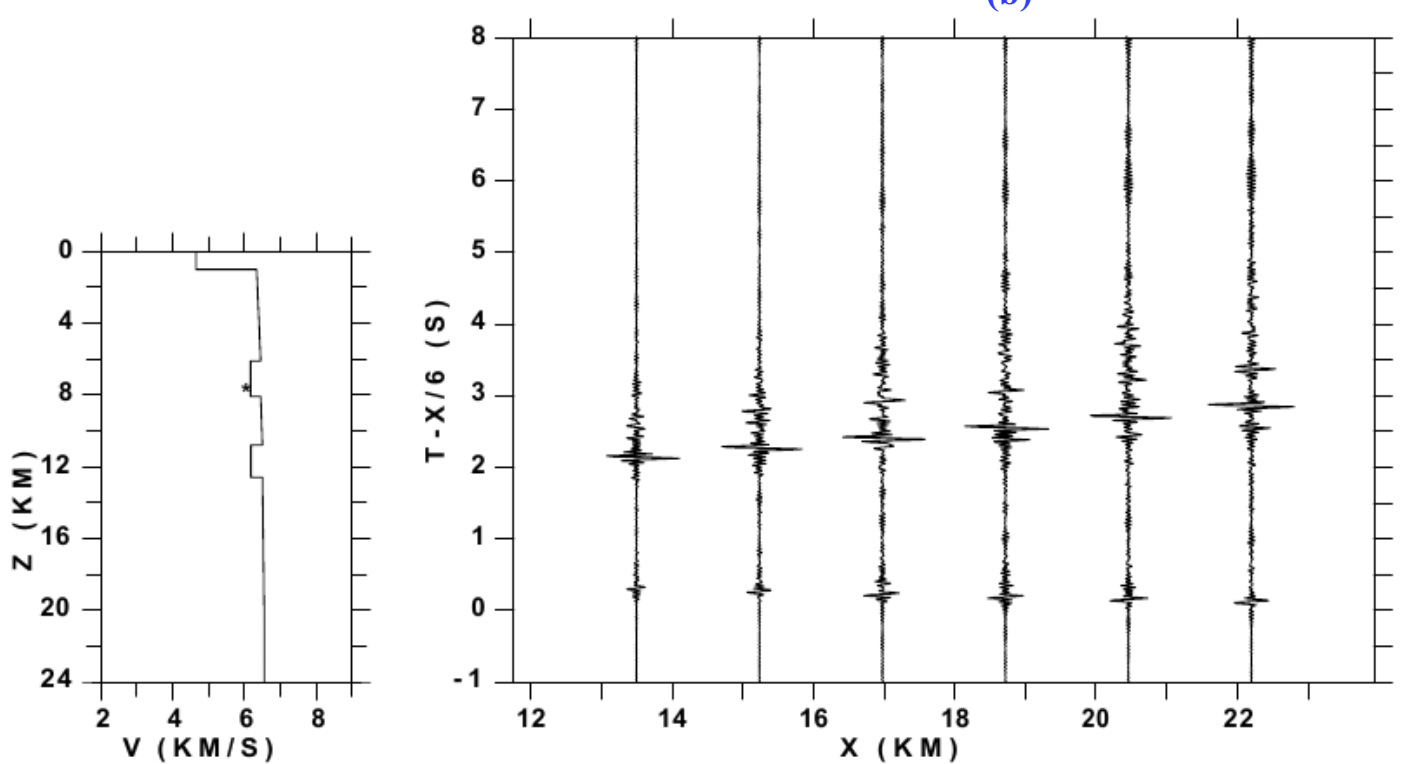

Figure 10. (a) Same as Figure 9a observed record section assembled from seismograms of local earthquakes with similar source mechanisms (the dominant mechanism is normal), aligned to an average source depth of $8 \mathrm{~km}$, and recorded at a combination of the seismograph stations CK, and FR in the Koyna-Warna region. Note significantly lower amplitudes of various phases, particularly P reflections and P-to$S$ conversions, as compared to those in Figure 9a. (b) Same as Figure $9 b$ synthetic seismogram section computed for a different set of the virtual source parameters and using the same inferred models of the upper crustal $\mathrm{P}$ and $\mathrm{S}$ velocity structure in the region. The amplitudes are trace-normalized. The left panel shows the same P velocity model as in Figure 9b.

\subsection{Travel times modeling}

The upper crustal $P$ and $S$ velocity models inferred from the INVSP (INverse Vertical Seismic Profiling) gather [Krishna 2006] for the station WR, are used as the initial models for travel times modeling computations. The following wave codes are considered for the purpose of illustration and modeling.

$P, S$ : up-going direct waves from a source as well as down-going refracted waves bottoming in the upper crustal layers and terminating on the free surface;

$\mathrm{Pi}$, Si: down-going waves from a source, reflected on i-th interface and terminating on the free surface (travel time curves are shown by continuous lines); and also

PfPi, SfSi, unlabeled and dotted: up-going waves from a source reflected on the free surface followed by a reflection on i-th interface and terminating on the free surface (travel time curves are shown by unlabeled dotted curves in the order for reflection on the $\mathrm{i}$-th interface, $i=1-4$ for both $P$ and $S$ phases)

Figure 11 illustrates the ray paths of various wave types described above. It is clear that these wave codes are by no means exhaustive, but they certainly represent a set of prominent $\mathrm{P}$ and $\mathrm{S}$ phases being considered for modeling the upper crustal velocity structure using the travel times. Possibly a large number of other multiples as well as converted phases from potential interfaces in the stratified upper crust, may be generated in the full wave synthetic seismogram computations il- 
A

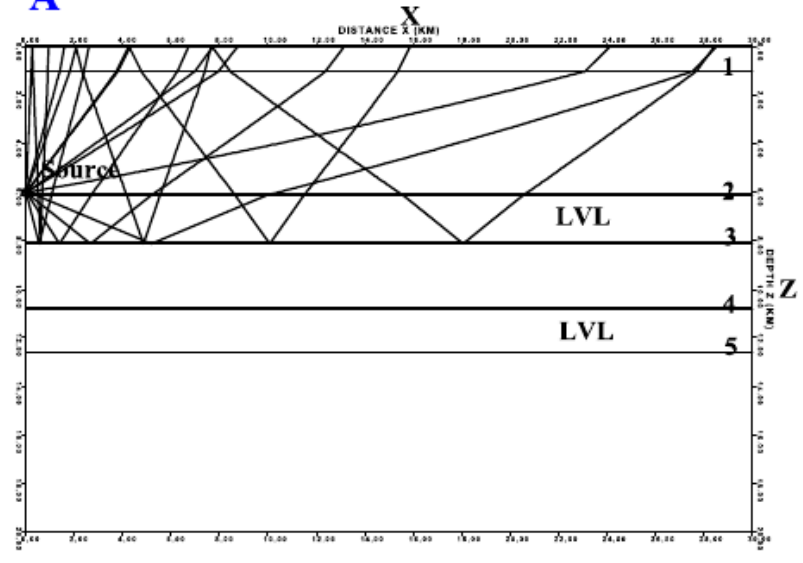

B

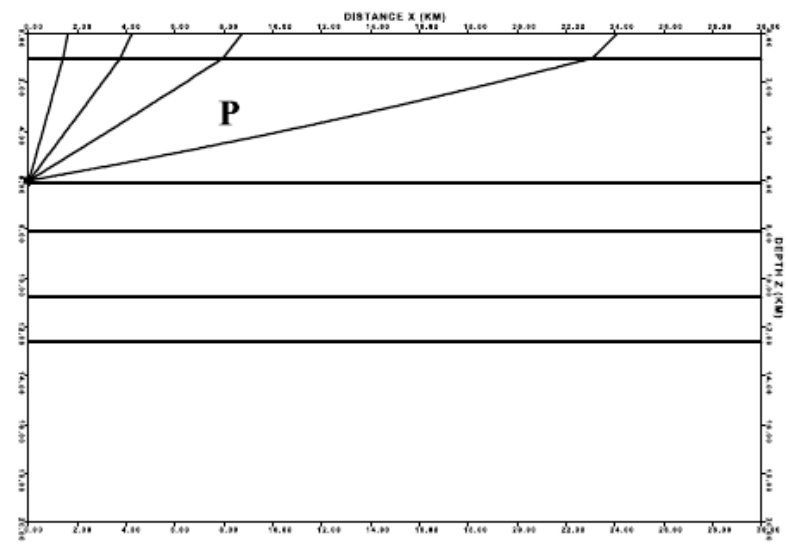

C

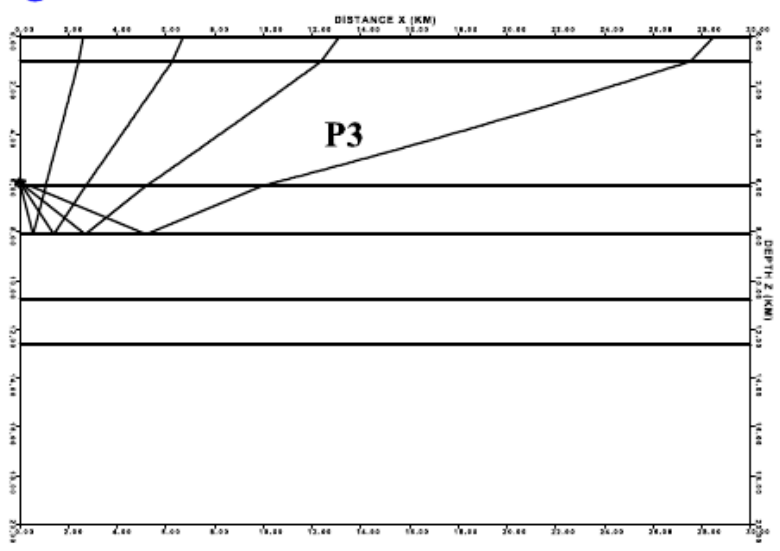

D

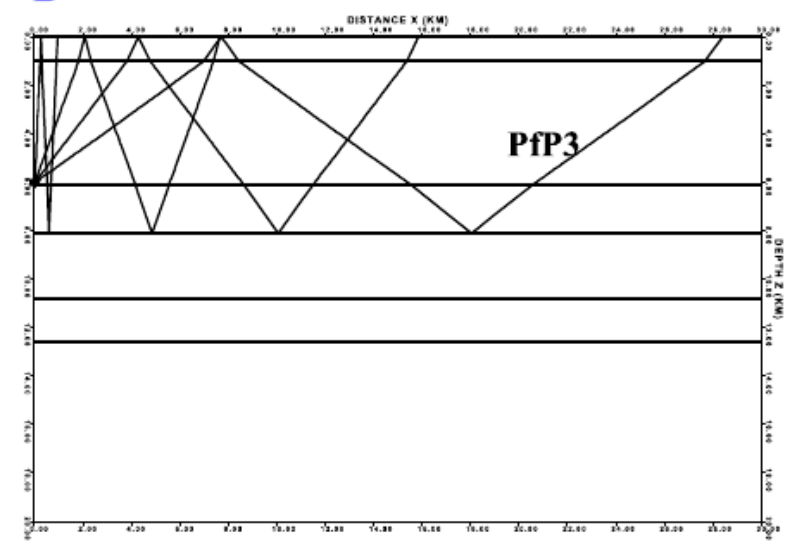

Figure 11. Schematic ray diagram illustrating the ray paths of prominent wave types considered for computing the $\mathrm{P}$ and $\mathrm{S}$ travel time curves given in Figures 9a and 10a. A: illustrates the upper crustal model, $B$ : illustrates the ray paths for P (or $S$ ), $C$ : illustrates the ray paths for $\mathrm{Pi}$ (or $\mathrm{Si}$ ), and $D$ : illustrates the ray paths for $\mathrm{PfPi}$ (or SfSi).

lustrated. Travel time computations for the $\mathrm{P}$ and $\mathrm{S}$ as well as the later arriving $\mathrm{Pi}$ and $\mathrm{Si}$ and the unlabeled phases (PfPi and $\mathrm{SfSi}$ ), consistent with the ray geometry (Figure 11) in the stratified upper crust as illustrated in Figure 2, for a good number of plausible velocity models starting with the initial models, are obtained. The travel time curves computed for the final models of upper crustal $P$ and $S$ velocity structure inferred in the study region are illustrated in the two observed record sections in Figures 9a and 10a. As can be seen from these figures, the travel times modeling substantiates qualitatively the viability of the upper crustal P and S velocity models and the stratified structure with presence of low-velocity layers (LVLs) inferred from the INVSP gather for the station WR in the Koyna-Warna region [Krishna 2006]. The synthetic seismogram sections, also illustrated in Figures $9 \mathrm{~b}$ and 10b, further confirm these models as discussed in the following.

\subsection{Synthetic seismograms modeling}

The travel times modeling of the Koyna-Warna local earthquake record sections given in the earlier section is limited to only a few prominent $\mathrm{P}$ and $\mathrm{S}$ phases in the stratified upper crust for inferring the preliminary models of the $\mathrm{P}$ and $\mathrm{S}$ velocity structure. The velocity models thus inferred are further substantiated with the aid of full wave synthetic seismogram computations for a set of source parameters (strike, dip, and rake) which are also progressively revised to generate the synthetic sections comparable to the observed sections (Figures 9a and 10a). The synthetics are generated for the 1-D isotropic Earth models in the present study.

Computation of synthetic seismograms in a layered half-space is an efficient technique for modeling the Earth's structure as well as the dynamic process of earthquake sources from well recorded seismic data. Many numerical techniques are well developed for generating synthetic seismograms for point sources in plane layered media in order to model observed datasets. The generalized ray and wavenumber integration techniques are however more commonly used in seismic modeling studies.

Fourier transform techniques require some form of wavenumber integration [e.g., Fuchs and Müller 1971, Kennett and Kerry 1979, Wang and Herrmann 1980, Bouchon 1981, Kind 1985, Müller 1985]. Wavenumber 
integration method for the generation of synthetic seismograms gives a complete solution, but can be computationally intensive. The complete solution, rather than individual rays, is considered in this full wave theory approach. This method can handle a larger number of plane layers, but requires considerable computational effort, especially at high frequencies. The reflectivity method for computing synthetic seismograms for an earthquake source [Kind 1985] is used for modeling the observed seismogram sections shown in Figures 9a and 10a.

A trial and error approach of forward computations, initially for refining the $\mathrm{P}$ and $\mathrm{S}$ velocity models and later for fixing the virtual source parameters (strike, dip, and rake), yielded acceptable fits (based on visual check) of the synthetic seismogram sections with the observed sections. Starting with the initial set of source parameters given in Table 2, each of the three parameters are varied fixing the other two, and in the process a good number of synthetics are computed for the same set of $\mathrm{P}$ and $\mathrm{S}$ velocity models obtained from travel times modeling. The virtual source parameters (strike, dip, and rake) are inferred for the record section
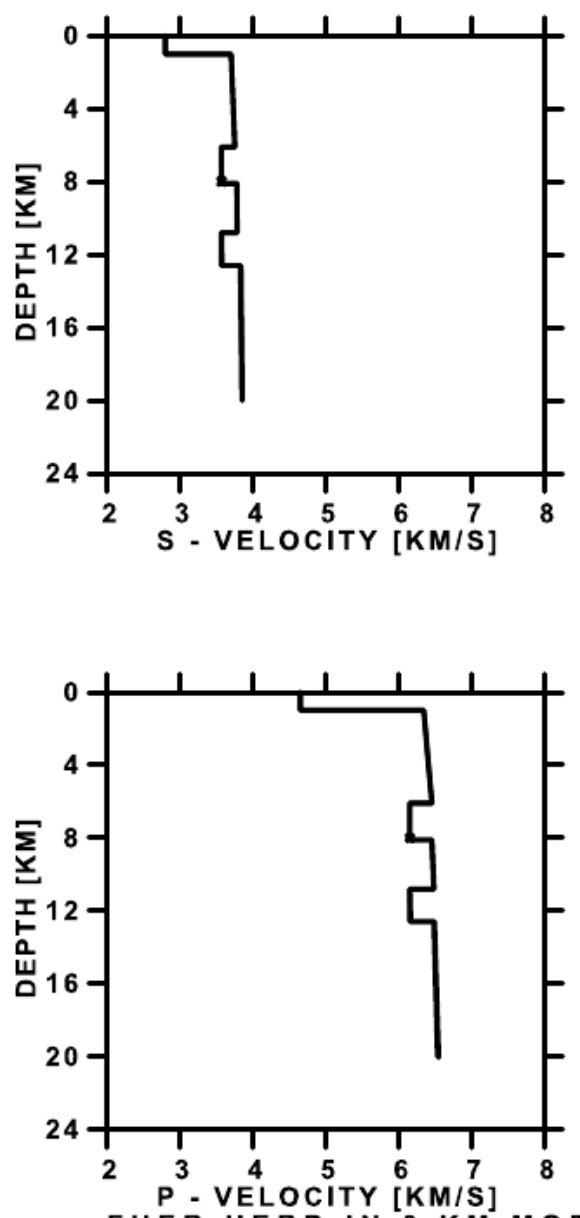

FUER HERD IN 8 KM MODELL KOYNA (assembled from earthquakes with different sets of the source parameters) being modeled. The azimuth used in the computations is the average azimuth for each of the observed sections in Figures 9 and 10. $Q_{P}$ and $Q_{S}$ in the upper crustal layers are initially used as those inferred in the nearby 1993 Latur earthquake area [Krishna et al. 1999]. The $Q_{P} / Q_{S}$ ratio is however suitably improved for the upper crust in order to obtain the synthetics that fit the observed sections. The final synthetic sections are selected based on the overall fits with the prominent phases in the observed sections, and shown in Figures $9 \mathrm{~b}$ and $10 \mathrm{~b}$. It may be noted here that the same set of the $\mathrm{P}$ and $\mathrm{S}$ velocity models, but different sets of the virtual source parameters (strike, dip, and rake), are used for modeling the sections in Figures 9a and 10a. It is significant to note that the same set of final $P$ and $S$ velocity models as shown in Figure 12 are able to reproduce the prominent features in both the seismogram sections, but different sets of the source parameters have to be used in order to generate the synthetics reasonably matching the observed sections. The viability of the inferred velocity models for the study region is thus established.

\section{Results and discussion}

The $\mathrm{P}$ and $\mathrm{S}$ velocity models and the resulting travel time curves given in Figure 12 are inferred from modeling the seismogram sections (Figures 9a and 10a) recorded at stations $\mathrm{CK}, \mathrm{FR}$, and SG. The maximum

\section{CK-FR-SG Source Depth 8Km}

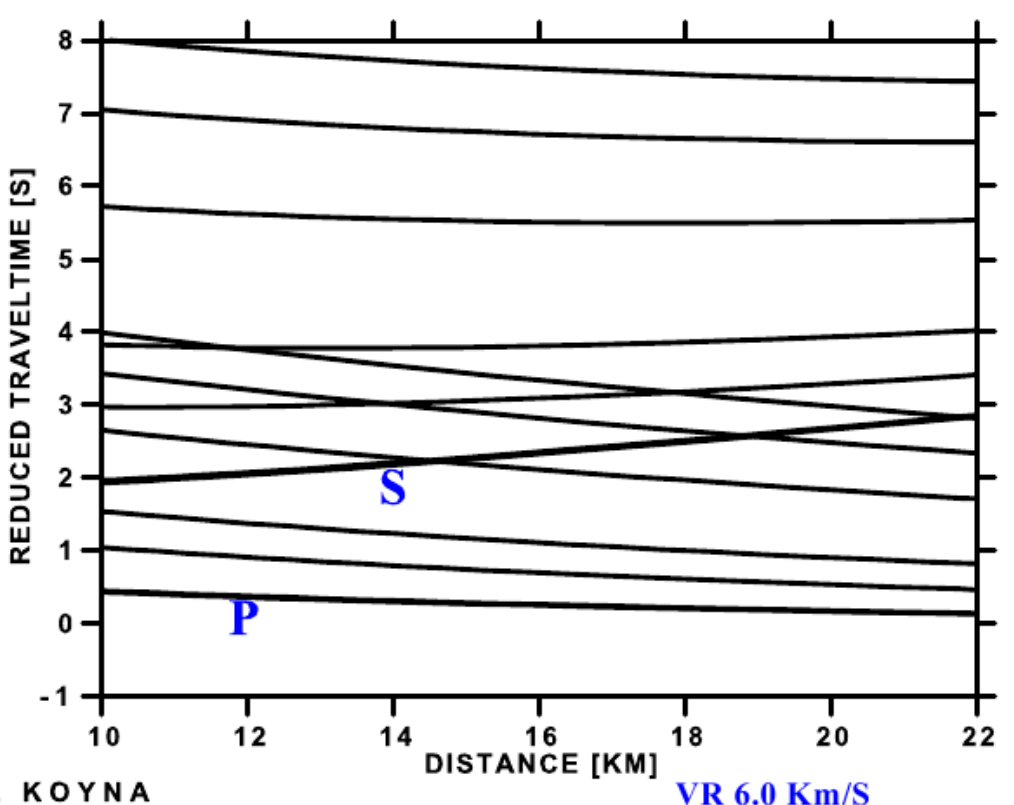

Figure 12. Inferred set of final $P$ and $S$ velocity models and the resulting travel time curves (for ray paths illustrated in Figure 11) reproducing the prominent features in both the seismogram sections (Figures 9 and 10), but with different sets of the source parameters in order to generate the synthetics reasonably matching both the observed sections. 
offset in the record sections modeled here is within $22 \mathrm{~km}$. Thus the inferred models are applicable to a limited area surrounding the epicentral region (see Figure 1a). These $P$ and $S$ velocity models are consistent with those obtained from modeling the $28 \mathrm{-km}$ constant offset INVSP gather at the seismograph station WR in the study region [Krishna 2006]. Significantly, the alternating LVLs with an average velocity reduction of about $0.30 \mathrm{~km} / \mathrm{s}(4 \%-5 \%)$ for P and about $0.18 \mathrm{~km} / \mathrm{s}(4 \%-5 \%)$ for $S$ waves at depths of $6.1-8.1 \mathrm{~km}$ and $10.8-12.6 \mathrm{~km}$ appear to be compatible with the travel times and synthetic seismograms generated (Figures 9 and 10 using different sets of virtual source parameters) in the present study. The ratio of $\mathrm{P}$ and $\mathrm{S}$ velocities $\mathrm{V}_{\mathrm{P}} / \mathrm{V}_{\mathrm{S}}$ in the upper crust is generally found to be $\sim 1.7$ in the study region. The $\mathrm{P}$ and $\mathrm{S}$ velocities in the upper crust (below a $1 \mathrm{~km}$ thick Deccan Traps layer with $\mathrm{V}_{\mathrm{P}} 4.65 \mathrm{~km} / \mathrm{s}$ and $\mathrm{V}_{\mathrm{S}} 2.80 \mathrm{~km} / \mathrm{s}$ as used in the present study) in the Koyna-Warna region are found to be varying from $6.34-6.45 \mathrm{~km} / \mathrm{s}$ and $3.70-3.75 \mathrm{~km} / \mathrm{s}$ (1.0-6.1 km depth), $6.45-6.48 \mathrm{~km} / \mathrm{s}$ and $3.78-3.83 \mathrm{~km} / \mathrm{s}$ (below the LVLs up to $12.6 \mathrm{~km}$ depth), and $6.15 \mathrm{~km} / \mathrm{s}$ and $3.57 \mathrm{~km} / \mathrm{s}$ in the

(a)

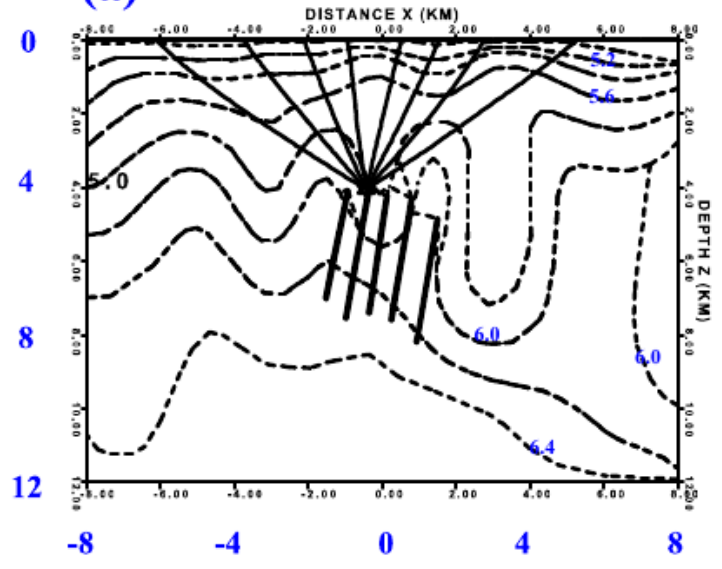

(b)

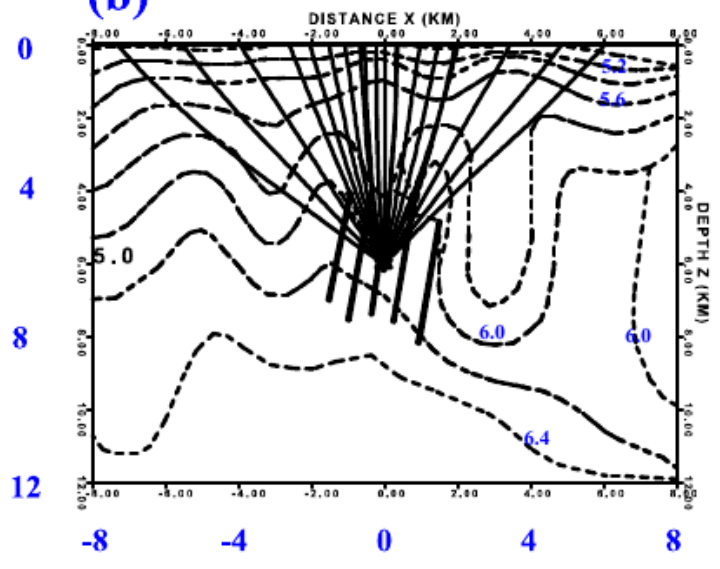

LVLs. Knowledge of the Deccan Traps thickness in the Koyna region and the nature of the underlying basement has been a subject of considerable interest. Recent results of scientific drilling (reported in 2013) through the Deccan Traps near Koyna has revealed about a $933 \mathrm{~m}$ thick pile of basaltic flows, which is found to underlain by granitic basement rocks. The Koyna Bore Hole-1 (KBH-1) located very near the Koyna Dam, in close proximity to the 1967 Koyna earthquake of magnitude 6.3, reached a depth of $951 \mathrm{~m}$ at the time of the report [Roy et al. 2013]. The transition from basalt to granite is marked by the occurrence of quartz and pink feldspar, followed by typical coarse grained granite deeper down.

The $\mathrm{P}$ velocity model considered by Srinagesh and Sarma [2005] for relocating the local earthquakes recorded by the Koyna-Warna digital network has a 1 $\mathrm{km}$ of the Deccan Traps layer with $V_{P} 4.70 \mathrm{~km} / \mathrm{s}$ underlain by the layer with $V_{P} 6.04 \mathrm{~km} / \mathrm{s}$ and increasing in steps to $6.56 \mathrm{~km} / \mathrm{s}$ at $16 \mathrm{~km}$ depth. Shashidhar et al. [2011] have estimated a $1.2 \mathrm{~km}$ thickness for the Deccan Traps layer with $V_{P} 4.40 \mathrm{~km} / \mathrm{s}$ underlain by a layer with
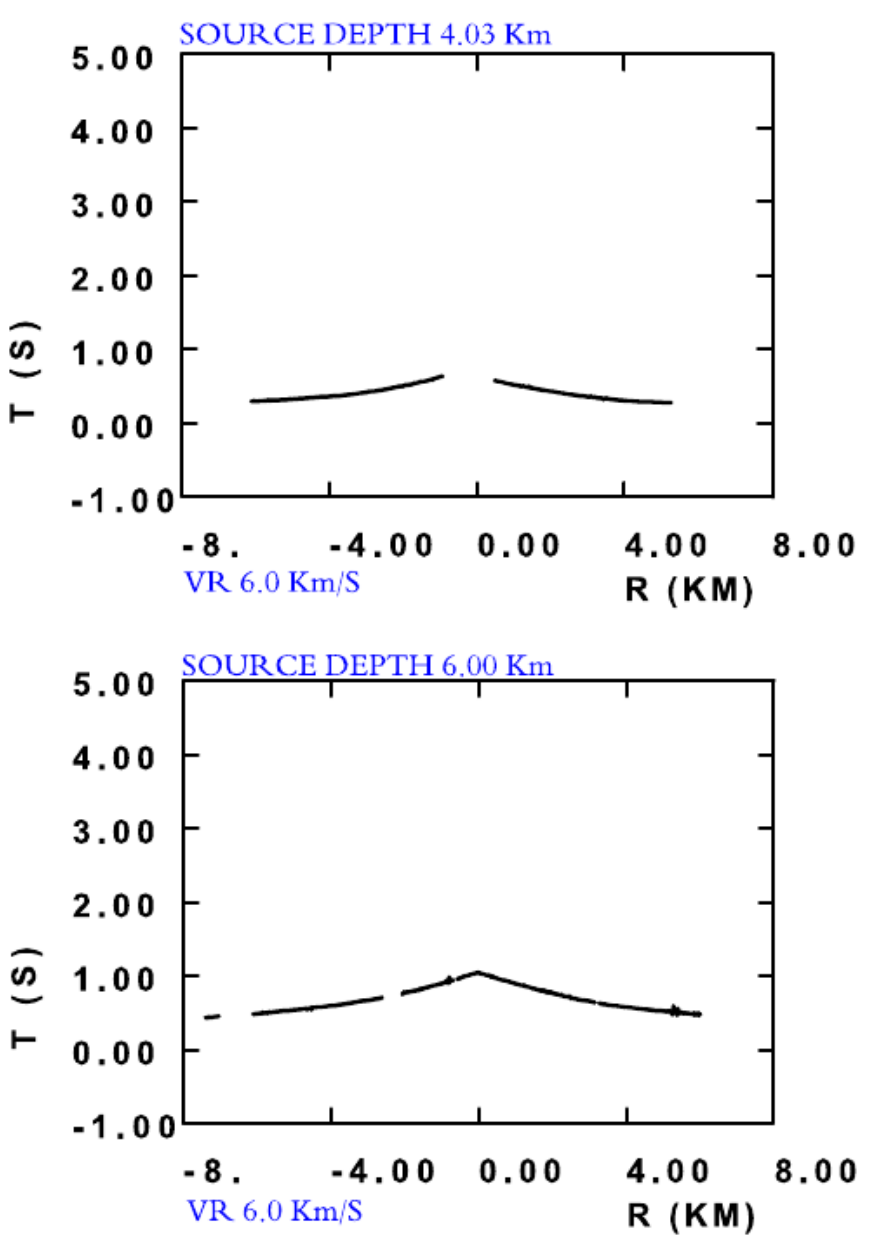

Figure 13. $\mathrm{V}_{\mathrm{p}}$ iso-velocity plots given by Dixit et al. [2014] for a limited region (as shown by a square near the seismograph station DH in Figure 1a) along with the ray paths obtained in the present study for two source depths at $\sim 4 \mathrm{~km}$ and $\sim 6 \mathrm{~km}$ and the resulting travel time curves for the direct $\mathrm{P}$ waves in the available offset range -8 to $8 \mathrm{~km}$. 
$\mathrm{V}_{\mathrm{p}} 5.96 \mathrm{~km} / \mathrm{s}$ in their model. However, the lower crustal layers in their model could not be resolved unambiguously. A recent study by Kilaru et al. [2015], based on the digital data set acquired by a dense network of 97 seismograph stations in the region, inferred a $1 \mathrm{~km}$ thick Deccan Traps layer with $V_{p} 4.81 \mathrm{~km} / \mathrm{s}$, followed by an upper crustal layer with $V_{\mathrm{p}} 5.94 \mathrm{~km} / \mathrm{s}$ down to $10 \mathrm{~km}$, and a middle crustal layer with $\mathrm{V}_{\mathrm{p}} 6.47 \mathrm{~km} / \mathrm{s}$ extending to $25 \mathrm{~km}$ depth. A comparison of these models with the velocity model inferred in the present study reveals that the Deccan Traps layer thickness and the $V_{\mathrm{P}}$ as well as the $\mathrm{V}_{\mathrm{P}} / \mathrm{V}_{\mathrm{S}}$ ratio agree quite well, and also the upper crustal $\mathrm{V}_{\mathrm{p}}$ at $\sim 10 \mathrm{~km}$ agrees well within $1 \%-2 \%$ in all the models. It may be noted here that all the 1-D velocity models inferred by Srinagesh and Sarma [2005], Shashidhar et al. [2011], and Kilaru et al. [2015] have been determined by VELEST software [Kissling 1988, Kissling et al. 1994]. It is generally recommended that, the VELEST runs have to begin without low-velocity layers (setting LOWVELOCLAY $=0$ by default) since they have strong effects on the ray paths and, thus, they increase the non-linearity of the problem. It is not clear whether presence of low-velocity layers in the upper crust in the study region is tested by any of these models. The inferred velocity models in the present study as well as those given by Krishna [2006] in this region significantly differ and clearly suggest presence of alternating lowvelocity layers in the upper crust based on interpretation of the coherent later arriving secondary $\mathrm{P}$ and $\mathrm{S}$ phases as plausible reflections from them. These model features are also consistently well revealed by at least more than 20 similar record sections compiled in the study region. It is thus believed that the upper crustal velocity models inferred in the present study are quite compatible with majority of the seismic record sections compiled by using the local earthquake recordings revealing the wave-field in the available range in the study region.

An attempt has also been made here to ray-trace through the complex velocity model recently given by Dixit et al. [2014] and generate the first arrival travel times in the near-offset range available in their model to $\sim 8 \mathrm{~km}$ distance from two sources at $\sim 4 \mathrm{~km}$ and $\sim 6 \mathrm{~km}$ depths. Figures $13 \mathrm{a}$ and $13 \mathrm{~b}$ show their $\mathrm{V}_{\mathrm{p}}$ iso-velocity plots along with the ray paths from the two source depths, and the resulting travel time curves for the direct $P$ waves in the offset range -8 to $8 \mathrm{~km}$. The region of study by Dixit et al. [2014] is indicated as a square area in Figure 1a, near the seismograph station DH. Figures $14 \mathrm{a}$ and $14 \mathrm{~b}$ show two record sections compiled in the region in the present study using the recordings at DH-WR stations for a source depth of $4 \mathrm{~km}$ and at DH-KN stations for a source depth of $6 \mathrm{~km}$. The $\mathrm{P}$ and $S$ travel time curves for the ray paths as given in Figure (a)
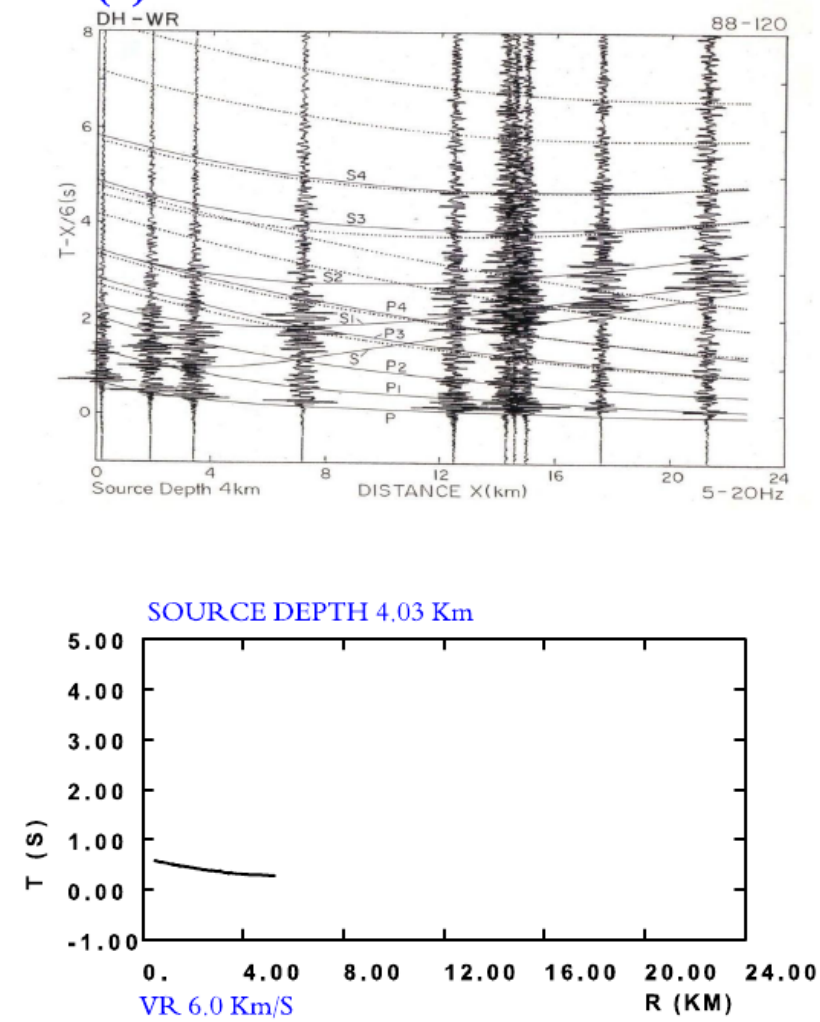

(b)
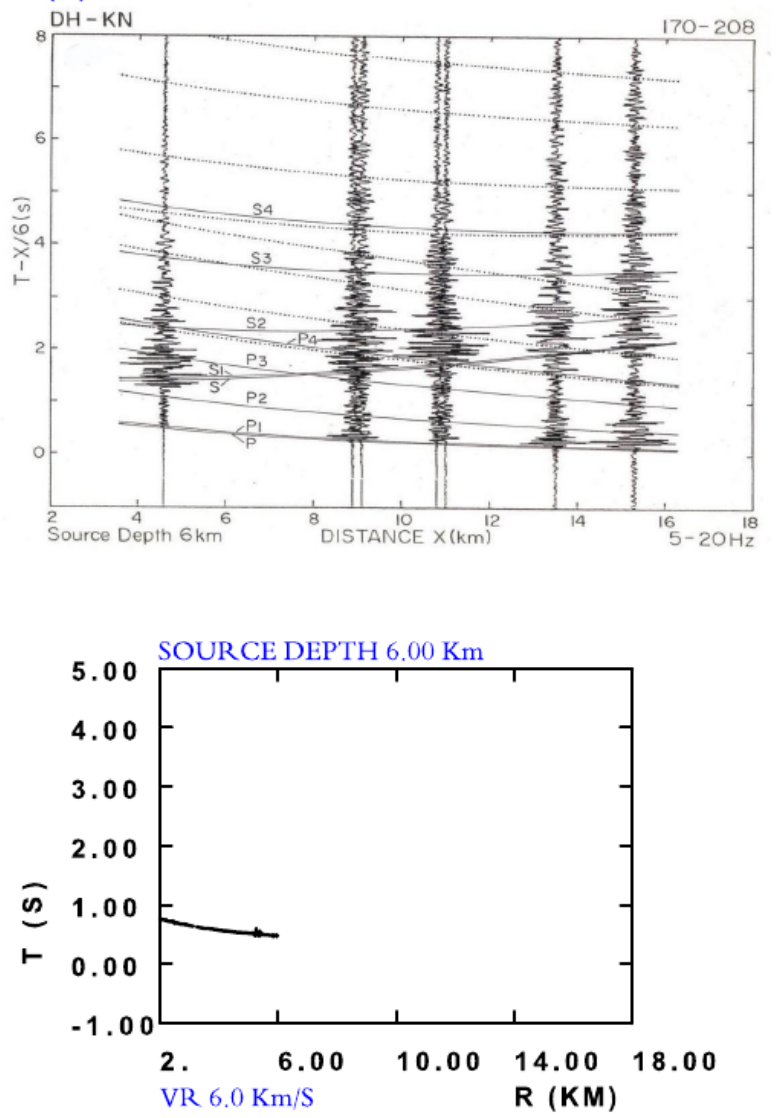

Figure 14. Two record sections compiled in the region in the present study, using the recordings at DH-WR stations for a source depth of $4 \mathrm{~km}$ and at DH-KN stations for a source depth of $6 \mathrm{~km}$. The $\mathrm{P}$ and $\mathrm{S}$ travel time curves for the ray paths as given in Figure 11 are also given in these two record sections. The direct $\mathrm{P}$ travel time curves computed for the model given by Dixit et al. [2014] are also indicated below these record sections. 
11 are also given in the two record sections. The direct $\mathrm{P}$ travel time curves computed for the model given by Dixit et al. [2014] are also indicated below these record sections. These travel times are found to be late by 0.030 $\mathrm{s}$ as compared to those obtained in the present study. Further, it is clear that the two record sections given in Figure 14 are more revealing as regards the upper crustal velocity structure in the region brought out with the aid of coherent and energetic secondary (reflection) phases. This is the great advantage of compiling the record sections using the local earthquake recordings in order to visualize the entire wave-field of interest and model the $\mathrm{P}$ and $\mathrm{S}$ velocity structure of the upper crust in the region of study. The recent and denser dataset collected by Dixit et al. [2014] may be more resourceful to generate a large number of record sections as shown in the present study. The presence or absence of the upper crustal low-velocity layers may also be investigated reliably by this approach. It is also well known that the presence of low-velocity layers is a challenge to first-arrival tomography, because the ray paths stay above these layers. This point is generalized to a notion that it is challenging for seismic tomography, especially travel time tomography, to resolve low-velocity anomalies because ray paths tend to stay away from them. Considering these problems, it is suggested compiling and modeling of a large number of local earthquake seismic record sections for several virtual sources in seismogenic regions as done in the present study may lead to reliable velocity models for the upper crust.

\section{Conclusions}

The present study, by several numerical simulations for varying source parameters, investigates an important problem concerning local earthquake seismogram characteristics, and their constraints for modeling the upper crustal velocity structure. Seismogram sections of local earthquakes with strike-slip mechanism are clearly more favorable in revealing the velocity stratification in the upper crust for both $\mathrm{P}$ and $\mathrm{S}$ waves. Specifically in seismogenic regions like the Koyna-Warna, where more than one type of source mechanisms are dominant within a short distance range, special care has to be taken to assemble the record sections of seismograms from events of similar source mechanisms. Seismogram sections of local earthquakes with normal, reverse, and dip-slip mechanisms particularly with rake angles around $\pm 90^{\circ}$ seem to display the upper crustal $\mathrm{P}$ and P-to-S converted phases poorly with low amplitudes, even in presence of sharp discontinuities of high velocity contrasts. Such record sections have to be modeled by considering the appropriate source mechanism and possibly by testing whether the synthetics obtained for significant stratification and high velocity contrasts consistently display low P amplitudes well matching the observed sections. It is clear that quite often the stratification resolved in the upper crust has important implications for the structure and physical state of the seismogenic crust. Especially the upper crustal low-velocity layers well resolved in seismogenic regions help understand the physical state of the earthquake source regions [Krishna et al. 1999].

\section{Data and resources}

A state-of-the-art digital seismograph network was deployed in the Koyna region during 1996-1998 to provide a reliable database for studying the Earth's structure and the seismicity in the region [Rai et al. 1999]. In the present study, we utilized the vertical component seismograms of local earthquakes well recorded by 3 stations selected from the Koyna digital seismograph network. The events were recorded (at 100 samples/s) by various stations of the seismograph network equipped with 24 bit REFTEK/PASSCAL digital recorders of short period three-component seismometers and GPS timing system. Local earthquake seismogram sections illustrated here are assembled by an approach discussed by Krishna et al. [1999]. Synthetic seismogram computations are made by using the reflectivity software developed by Kind [1985] for an earthquake source.

Acknowledgements. I am grateful to Prof. Dr. Harsh K. Gupta, Panikkar Professor at the CSIR - National Geophysical Research Institute, Hyderabad, for inviting me to process and model the valuable dataset of local earthquake seismograms to derive the upper crustal velocity structure in the Koyna-Warna seismic region, as well as for his helpful discussions concerning this research. I gratefully acknowledge the kind advice of Prof. Dr. R. Kind, GFZ, Germany, for successful implementation of his reflectivity software in the Windows 7-CYGWIN 64 system, extensively used for rapid computation of a large number of synthetic seismogram sections in the present study. Prof. Dr. Friedemann Wenzel of KIT, Universitaet Karlsruhe, Germany contributed by helpful discussions. Prof. Dr. S.S. Rai while at NGRI, made available the digital seismograms data of local earthquakes acquired by their research group in the KoynaWarna seismic region illustrated here. Computations were made on a VAX-3100 system, and on a Windows 7-CYGWIN 64 system.

\section{References}

Aagaard, B.T., J.F. Hall and T.H. Heaton (2001a). Characterization of near-source ground motion with earthquake simulations, Earthq. Spectra, 17, 177-207.

Aagaard, B.T., T.H. Heaton and J.F. Hall (2001b). Dynamic earthquake ruptures in the presence of litho static normal stresses: implications for friction models and heat production, B. Seismol. Soc. Am., 91, 1765-1796.

Aagaard, B.T., J.F. Hall and T.H. Heaton (2004). Effects of fault dip and slip rake angles on near-source ground 
motions: why rupture directivity was minimal in the 1999 Chi-Chi, Taiwan earthquake, B. Seismol. Soc. Am., 94, 155-170.

Bouchon, M. (1981), A simple method to calculate Green's functions for elastic layered media, B. Seismol. Soc. Am., 71, 959-971.

Brüstle, W., and G. Müller (1983). Moment and duration of shallow earthquakes from Love-wave modeling for regional distances, Phys. Earth Planet. Inter., 32, 312-324.

Dixit, M.M., S. Kumar, R.D. Catchings, K. Suman, D. Sarkar and M.K. Sen (2014). Seismicity, faulting, and structure of the Koyna-Warna seismic region, Western India from local earthquake tomography and hypocenter locations, J. Geophys. Res., Solid Earth, 119, 6372-6398; doi:10.1002/2014JB010950.

Dreger, D.S., and D.V. Helmberger (1993). Determination of source parameters at regional distances with three-component sparse network data, J. Geophys. Res., 98, 8107-8125.

Fuchs, K., and G. Müller (1971). Computation of synthetic seismograms with the reflectivity method and comparison with observations, Geophys. J. Roy. Astr. S., 23, 417-433.

Gahalaut, V.K., Kalpna and S.K. Singh (2004). Fault interaction and earthquake triggering in the KoynaWarna region, India, Geophys. Res. Lett., 31, L11614; doi:10.1029/2004GL019818.

Gupta, H.K., H. Narain, B.K. Rastogi and I. Mohan (1969). A study of the Koyna Earthquake of December 10, 1967, B. Seismol. Soc. Am., 59, 1149-1162.

Gupta, H.K., B.K. Rastogi and H. Narain (1972). Some discriminatory characteristics of Earthquakes near the Kariba, Kremasta and Koyna artificial lakes, B. Seismol. Soc. Am., 62, 493-507.

Gupta, H.K., and B.K. Rastogi (1974). Will another damaging earthquake occur in Koyna?, Nature, 248, 214-216.

Gupta, H. K., and B.K. Rastogi (1976). Dams and Earthquakes, 1st ed., Elsevier Scientific Publishing Company, Amsterdam, $372 \mathrm{p}$.

Gupta, H.K., C.V.R.K. Rao and B.K. Rastogi (1980). An investigation of earthquakes in Koyna region, Maharashtra, for the period October 1973 through December 1976, B. Seismol. Soc. Am., 70, 1833-1847.

Gupta, H.K. (1985). The present status of the reservoirinduced seismicity with the special emphasis on Koyna Earthquake, Tectonophysics, 118, 257-507.

Gupta, H.K. (1992). Reservoir Induced Earthquakes, Elsevier Publishers, Amsterdam, 364 p.

Gupta, H.K. (2002). A review of recent studies of triggered earthquakes by artificial water reservoirs with special emphasis on earthquakes in Koyna, India,
Earth-Sci. Rev., 58, 279-310.

Gupta, H.K. (2005). Artificial water reservoir-triggered earthquakes with special emphasis at Koyna, Curr. Sci., 88 (10), 1628-1631.

Gupta, H.K., N.P. Rao, D. Shashidhar, N. Mallika and S. Roy (2012). Deep scientific drilling to study Reservoir Triggered Earthquakes at Koyna, India, in Deep Continental Studies in India, Newsletter, Department of Science and Technology, Government of India, New Delhi, 22, 2-8.

Hartzell, S.H., and T.H. Heaton (1983). Inversion of strong ground motion and teleseismic waveform data for the fault rupture history of the 1979 Imperial Valley, California, earthquake, B. Seismol. Soc. Am., 73, 1553-1583.

Kennett, B.L.N., and N.J. Kerry (1979). Seismic waves in a stratified half-space, Geophys. J. Roy. Astr. S., 57, 557-583.

Kilaru, S., S. Kumar, M.M. Dixit and P. Rama Rao (2015). 1 -D velocity model delineated using dense seismic network in the Koyna-Warna region, Maharashtra, India, J. Ind. Geophys. Union, 19 (2), 182-189.

Kind, R. (1985). The reflectivity method for different source and receiver structures and comparison with GRF data, J. Geophys., 58, 146-152.

Kissling, E.W. (1988). Geotomography with local earthquake data, Rev. Geophys., 26, 659-698.

Kissling, E.W., W.L. Ellsworth, D. Eberhart-Phillips and U. Kradolfer (1994). Initial reference models in local earthquake tomography, J. Geophys. Res., 99, 1963519646.

Krishna, B., N. Negi and J.G. Negi (1973). Rift valley beneath Deccan Traps (India), Geophys. Res. Bull., 2, 207-237.

Krishna, V.G., C.V.R.K. Rao, H.K. Gupta, D. Sarkar and M. Baumbach (1999). Crustal seismic velocity structure in the epicentral region of the Latur earthquake (September 29, 1993), southern India: inferences from modeling of the aftershock seismograms, Tectonophysics, 304, 241-255.

Krishna, V.G., and D.S. Ramesh (2000). Propagation of crustal-waveguide-trapped $\mathrm{Pg}$ and seismic velocity structure in the South Indian shield, B. Seismol. Soc. Am., 90, 1281-1294.

Krishna, V.G. (2006). INVSP gathers of local earthquake seismograms: an approach for modelling the upper crustal P and S velocity structure, Geophys. J. Int., 166, 148-154.

Krishna, V.G. (under review). An approach of refraction seismology for processing and modelling of local earthquake seismogram sections of virtual sources at multiple depths in seismogenic regions - Application to Koyna-Warna region, India for upper crustal 
$\mathrm{P}$ and $\mathrm{S}$ velocity structure; submitted to Annals of Geophysics, under review.

Langston, C.A. (1981). Source inversion of seismic waveforms: the Koyna, India, earthquakes of 13 September 1967, B. Seismol. Soc. Am., 71, 1-24.

Müller, G. (1985). The reflectivity method: a tutorial, J. Geophys., 58, 153-174.

Oglesby, D.D., R.J. Archuleta and S.B. Nielsen (2000). The three-dimensional dynamics of dipping faults, B. Seismol. Soc. Am., 90, 616-628.

Rai, S.S., S.K. Singh, P.V.S.S. Rajagopal Sarma, D. SriNagesh, K.N.S. Reddy, K.S. Prakasam and Y. Satyanarayana (1999). What triggers Koyna region earthquakes? Preliminary results from seismic tomography digital array, Proc. Indian Acad. Sci. (Earth Planet. Sci.), 108, 1-14.

Sarma, P.R., and D. Srinagesh (2007). Improved earthquake locations in the Koyna-Warna seismic zone, Nat. Hazards, 40, 563-571.

Sharma, J. (2000). Focal mechanism studies in KoynaWarna seismic zone, M.Tech. dissertation, Kurukshetra Univ., India, $38 \mathrm{p}$.

Shashidhar, D., N. Purnachandra Rao and H. Gupta (2011). Waveform inversion of broad-band data of local earthquakes in the Koyna-Warna region, Western India, Geophys. J. Int., 185, 292-304.

Srinagesh, D., and P.R. Sarma (2005). High precision earthquake locations in Koyna-Warna seismic zone reveal depth variation in brittle-ductile transition zone, Geophys. Res. Lett., 32, L08310; doi:10.1029/ 2004GL022073.

Roy, S., N.P. Rao, V.V. Akkiraju, D. Goswami, M. Sen, H. Gupta, B.K. Bansal and S. Nayak (2013). Granitic Basement below Deccan Traps Unearthed by Drilling in the Koyna Seismic Zone, Western India, NEWS AND NOTES, J. Geol. Soc. India, 81, 289-290.

Talwani, P. (1997). Seismotectonics of the Koyna-Warna area, India, Pure Appl. Geophys., 150, 511-550.

Wadia, D.N. (1968). The Koyna earthquake, December 1967, special number on Koyna earthquake 11th December 1967, J. Indian Geophys. Union, 5, 6-8.

Wang, C.Y., and R.B. Herrmann (1980). A numerical study of P-, SV-, and SH-Wave generation in a plane layered medium, B. Seismol. Soc. Am., 70, 10151036.

\footnotetext{
${ }^{\star}$ Corresponding author: V.G. Krishna, 10-2-267/2, Fashions' Apts., West Marredpally, Secunderabad500026, India; email: v_gopalak@yahoo.com, gopalakrishna.velamakanni@gmail.com. 